\title{
Properties and Reactivities of Niclosamide in Different Media, a Potential Antiviral to Treatment of COVID-19 by Using DFT Calculations and Molecular Docking
}

\author{
Davide Romani ${ }^{1}$, Olfa Noureddine ${ }^{2}$, Noureddine Issaoui ${ }^{2}$, Silvia Antonia Brandán ${ }^{3, * \text { (D) }}$ \\ 1 Dipartimento di Scienze Mediche Chirurgiche e Neuroscienze, Università degli Studi di Siena, Via Banchi di Sotto 55 \\ (53100), Siena, Italia; dromaniti@gmail.com; \\ 2 University of Monastir, Laboratory of Quantum and Statistical Physics (LR18ES18), Faculty of Sciences, Monastir 5079, \\ Tunisia.; issaoui_noureddine@yahoo.fr; \\ 3 Cátedra de Química General, Instituto de Química Inorgánica, Facultad de Bioquímica, Química y Farmacia, Universidad \\ Nacional de Tucumán, Ayacucho 471, (4000), San Miguel de Tucumán, Tucumán, Argentina \\ * Correspondence: sbrandan@fbqf.unt.edu.ar;
}

Scopus Author ID 6602262428

Received: 9.05.2020; Revised: 3.06.2020; Accepted: 5.06.2020; Published: 8.06.2020

\begin{abstract}
In this work, the structural, electronic, topological and vibrational properties of potential antiviral to treatment of COVID-19, niclosamide (NCL) have been studied in different media together with its reactivities by combination of DFT calculations with molecular docking. Properties of two most stable conformers of niclosamide ( $\mathrm{C} 1$ and $\mathrm{C} 2)$ were reported in gas phase and water, ethanol and chloroform solvents. Calculations using the integral equation formalism variant polarised continuum (IEFPCM) and solvation methods in the different solutions have revealed solvation energy values for $\mathrm{C} 1$ and $\mathrm{C} 2$ in aqueous solution $\left(\Delta \mathrm{G}_{\mathrm{C}}=-78.43\right.$ and $-64.53 \mathrm{~kJ} / \mathrm{mol}$, respectively) comparable with that observed for the antiviral agent zalcitabine $(-78.92 \mathrm{~kJ} / \mathrm{mol})$. Probably, the high stability of $\mathrm{C} 1$, predicted by NBO studies, explains the experimental existence of $\mathrm{C} 1$ in the solid phase. Comparisons of frontier orbitals with eleven antiviral agents have evidenced the high reactivity of $\mathrm{C} 2$ slightly higher than brincidofovir, an antiviral agent used in the treatment to ebola disease. Possibly, the presence of deactivating groups $\left(\mathrm{NO}_{2}\right.$ and $\left.\mathrm{Cl}\right)$ in the chloro-4-nitrophenyl and hydroxybenzamide rings of both forms of NCL could explain the higher reactivities predicted in the different media. Here, the harmonic force fields and force constants for both forms are reported together with the assignments of 80 vibration modes expected in the experimental infrared spectrum of NCL. The predicted UV-Vis spectra in the different solvents suggest the presence of both forms of NCL in solution. Molecular docking results were discussed basing on the type of interaction between the ligands and several amino acid residues.
\end{abstract}

Keywords: Niclosamide; vibrational spectra; molecular structure; descriptor properties; DFT calculations

(C) 2020 by the authors. This article is an open-access article distributed under the terms and conditions of the Creative Commons Attribution (CC BY) license (https://creativecommons.org/licenses/by/4.0/).

\section{Introduction}

The great world problem at present is the treatment of the deadly coronavirus disease 2019 named "severe acute respiratory syndrome coronavirus 2" (SARS-CoV-2) that is affecting the world population [1-20]. The identification and characterization of novel 2019nCoV were performed by Zhu et al. [3] whose have revealed that the new 2019-nCoV presents from 75 to $80 \%$ equivalent to the SARS-CoV and even more closely related to several bat coronaviruses [4]. The crystal structure of 2019-nCoV main protease in complex with an inhibitor N3 was identified [5]. In contrast, the inhibitor N3 was previously published by Yang 
et al. [6]. In this context, the investigations are directed to the development of therapeutic agents and vaccines for COVID-19 and related human coronavirus diseases $[9,10]$. The need to find an effective antiviral agent is urgent; so many researchers are working on the design of effective antiviral agents with few side effects. So, recently Xu et al. [12] have suggested niclosamide (NCL) as a potential antiviral agent because it drug is effective against various viral infections with nanomolar to micromolar potencies such as SARS-CoV, MERS-CoV, ZIKV, HCV, and human adenovirus. Structures of compounds clinically used as antiviral drugs for the treatment of numerous infections, such as human immunodeficiency virus (HIV), of chronic hepatitis B virus (HBV) and hepatitis $\mathrm{C}$ virus (HCV), of herpes simplex virus (HSV) and/or varicellazoster virus (VZV), or cytomegalovirus (CMV, of influenza virus and, of respiratory syncytial virus (RSV) have been carefully detailed by Clerk including their activity spectral, mechanisms of action, principal indications and administration [21,22]. Hence, those compounds together with other antiviral agents are known from a biological point of view, while the structural, electronic, topological, and vibrational properties only for some of them were studied combining available experimental results with theoretical DFT calculations [23-32]. Here, the structural, electronic, topological, and vibrational properties of two conformers most stable of niclosamide, 5-Chloro-N-(2-chloro-4-nitrophenyl)-2-hydroxybenzamide, were reported in the gas phase and water, ethanol and chloroform solvents by using DFT calculations and molecular docking. It drug was studied in different media because studies on cocrystals of NCL have evidenced its low solubility and high permeability [33] and, for these reasons, here, investigations of reactivities and behaviors in the different solvents for both forms were performed. Those properties, together with the NCL solubility in different solvents, are essential, taking into account the expected potential biological activities and the presence of donors and acceptors groups in the structure. Here, the solvation energy values, atomic charges, stabilization energies, molecular electrostatic potentials, bond orders, and reactivities were evaluated as a function of the solvent's permittivity values. On the other hand, the bands observed in the experimental available infrared spectrum were assigned combining the B3LYP/6-31G* calculations with the SQMFF methodology and the Molvib program [34-36]. Hence, the harmonic force constants in the different media are also reported. The predicted properties for NCL were compared with those published for other antiviral agents [23-32]. In addition, a molecular docking study was performed for NCL because it is an essential method in molecular modeling applications and drug discovery.

\section{Materials and Methods}

The initial structure of NCL was taken from the CIF file because its experimental structure was determined by Sanphui et al. [37] by using X-ray diffraction. The GaussView program and the Revision A.02 of the Gaussian program [38,39] were employed to optimize the structures of NCL in the different media with the functional hybrid B3LYP/6-31G* method $[40,41]$. That basis set was used because the properties of compared antiviral compounds were published with that level of theory. Both IEFPCM and universal solvation methods employed here to consider the solvent effects [42-44]. With the optimized structure in the gas phase, the potential energy surfaces (PES) were investigated for variations of dihedral N7-C11-C10-C14 and $\mathrm{C} 10-\mathrm{C} 14-\mathrm{O} 3-\mathrm{H} 29$ angles at the same level of theory. Then, two stable structures, named $\mathrm{C} 1$ and $\mathrm{C} 2$, were found in the PES, where $\mathrm{C} 2$ presents the global minimum and where both can be seen in Figure 1. 


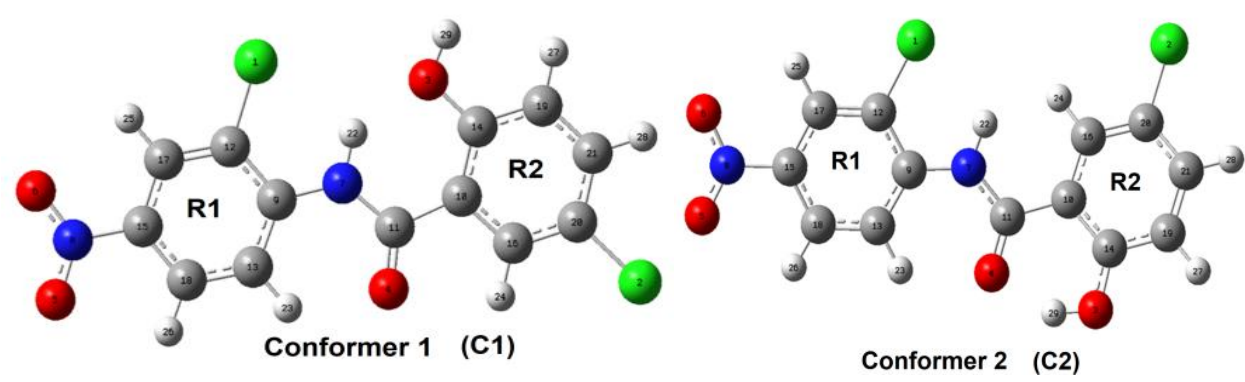

Figure 1. Molecular structures of the two most stable conformers of niclosamide (5-Chloro-N-(2-chloro-4nitrophenyl)-2-hydroxybenzamide), identifications of both rings and atoms numbering.

Here, it is necessary to clarify that the experimental structure of NCL determined by Sanphui et al. [37] corresponds to conformer C1, but the theoretically most stable structure of NCL is C2. Volumes and their differences were computed with the Moldraw program [45]. Versions 3.2 and 2000 of NBO and AIM programs respectively were used to calculate atomic charges, molecular electrostatic potentials, bond orders, and topological properties [46-48] while the reactivities and behaviors in the different media were predicted by using frontier orbitals and equations reported for some typical descriptors [49-56]. Usual internal coordinates of NCL, transferable scaling factors, and the scaled mechanical force field (SQMFF) methodology, together with version 7.0 of the Molvib program, were used to calculate the harmonic force fields and force constants [34-36]. Then, the vibrational study was performed using potential energy distribution (PED) contributions $\geq 10 \%$.

All molecular docking calculations for niclosamide (NCL) are made using iGEMDOCK [57] on the basis of GEMDOCK (Generic Evolutionary Method for Docking Molecules) scoring function [58]. The choice of ligands was mainly based on their antiinflammatory and antiviral activities. It is worthy of mentioning that the novel 2019-nCoV has the same symptoms as a flue. It can cause fatigue, fever, and cough, which may be accompanied by nasal congestion, runny nose, headache, expectoration, diarrhea, etc. The election was performed, taking into account that information. Before starting the molecular docking calculations, the structure of Coronavirus 2019 (COVID-19) is extracted from the Protein Data Bank [5] of the Structural Bioinformatics Research Laboratory (RCSB) (PDB ID: 6LU7 ). Subsequently, it is cleaned of possible undesirable entities such as water molecules by the Discovery Studio program [59]. NCL was tested as 2019-nCoV inhibitors and was docked at the binding site of 2019-nCoV to shed light on their potential binding modes. The p-tau proteinligand complex was calculated by measuring various non-polar and polar interactions, for instance, van der Waal's interactions, electrostatic interactions, and H-bonding interaction interactions for each ligand.

\section{Results and Discussion}

\subsection{Optimizations and properties in different media.}

Both stable molecular structures of NCL and atoms numbering are shown in Figure 1, together with the identification of two rings. Rings containing both chloro and nitrophenyl groups are named R1, while R2 is named to the rings that contain to hydroxybenzamide moieties. Calculated total and corrected by zero-point vibrational energy (ZPVE), dipole moments $(\mu)$ and volumes $(\mathrm{V})$ of both conformers of NCL in the gas phase and aqueous, ethanol and chloroform solutions by using B3LYP/6-31G* level of theory together with the 
permittivity's $(\varepsilon)$ values can be seen in Table 1. Higher energy values are observed for $\mathrm{C} 1$ and $\mathrm{C} 2$ in chloroform solution, although the dipole moment values have higher values in water, and its higher volumes are observed in ethanol. Besides, for both conformers, the dipole moment values increase according to increases the permittivity of the solvent, although the volume values do not follow a defined trend. Variations energy values among both forms show that $\mathrm{C} 1$ and $\mathrm{C} 2$ could exist in the different solutions because in the gas phase $\Delta \mathrm{E}$ is $20.46 \mathrm{~kJ} / \mathrm{mol}$ while the values decrease in chloroform, ethanol, and water respectively to $12.06,6.82$ and 7.34 $\mathrm{kJ} / \mathrm{mol}$. This way, the values predicted in solutions are low enough, as compared with the values in the gas phase. Table 2 are presented corrected solvation energies and uncorrected by ZPVE energies together with the volumes variations for $\mathrm{C} 1$ and $\mathrm{C} 2$ of NCL in the gas phase and the three solvents by using the B3LYP/6-31G* level of theory.

Table 1. Calculated total and corrected by ZPVE energies $(E)$, dipole moments $(\mu)$, and volumes $(\mathrm{V})$ of niclosamide in the gas phase and aqueous, ethanol and chloroform solutions by using B3LYP/6-31G* level of theory. Permittivity's $(\varepsilon)$ values of all species are also included.

\begin{tabular}{|c|c|c|c|c|c|}
\hline \multicolumn{6}{|c|}{ B3LYP/6-31G* Method } \\
\hline \multicolumn{6}{|c|}{ Conformer C1 } \\
\hline Species & E (Hartrees) & E ZPVE & $\mu(\mathrm{D})$ & $\mathrm{V}\left(\AA^{3}\right)$ & $\varepsilon$ \\
\hline Gas & -1830.9136 & $-1830,7170$ & 7,95 & 278,9 & 1 \\
\hline Chloroform & -1830.9391 & $-1830,7426$ & 9,77 & 278,8 & 4.7113 \\
\hline Ethanol & -1830.9382 & -1830.7423 & 10,93 & 285,2 & 24.852 \\
\hline Water & -1830.9294 & $-1830,7337$ & 11,25 & 282,8 & 78.3553 \\
\hline \multicolumn{6}{|c|}{ Conformer $\mathrm{C} 2$} \\
\hline Species & E (Hartrees) & E ZPVE & $\mu(\mathrm{D})$ & $\mathrm{V}\left(\AA^{3}\right)$ & $\varepsilon$ \\
\hline Gas & -1830.9214 & -1830.7241 & 3.96 & 281.5 & 1 \\
\hline Chloroform & -1830.9437 & -1830.7465 & 4.74 & 286.3 & 4.7113 \\
\hline Ethanol & -1830.9408 & -1830.7440 & 5.43 & 287.7 & 24.852 \\
\hline Water & -1830.9322 & -1830.7356 & 5.65 & 286.3 & 78.3553 \\
\hline
\end{tabular}

Table 2. Corrected solvation energies $\left(\Delta \mathrm{G}_{\mathrm{C} / Z \mathrm{ZPE}}\right)$ and uncorrected by ZPVE energies $\left(\Delta \mathrm{G}_{\mathrm{C}}\right)$ and volumes variations $(\Delta \mathrm{V})$ of niclosamide in the gas phase and aqueous, ethanol and chloroform solutions by using B3LYP/6-31G* level of theory.

\begin{tabular}{l|c|c|c|c|c}
\hline \multicolumn{7}{c}{ B3LYP/6-31G* Method } \\
\hline \multicolumn{7}{c}{ Species } & $\Delta \mathrm{G}_{\text {un }}$ & $\Delta \mathrm{G}_{\mathrm{ne}}$ & $\Delta \mathrm{G}_{\mathrm{C}}$ & $\Delta \mathrm{V}\left(\AA^{3}\right)$ & $\Delta \mathrm{G}_{\mathrm{C} / \mathrm{ZPVE}}$ \\
\hline Chloroform & -66.89 & -21.53 & -45.36 & -0.1 & -45.62 \\
\hline Ethanol & -64.52 & 8.07 & -72.59 & 6.3 & -78.89 \\
\hline Water & -41.44 & 36.99 & -78.43 & 3.9 & -80.79 \\
\hline \multicolumn{7}{c}{ Species } & $\Delta \mathrm{G}_{\mathrm{un}}$ & $\Delta \mathrm{G}_{\mathrm{ne}}$ & $\Delta \mathrm{G}_{\mathrm{C}}$ & $\Delta \mathrm{V}\left(\AA^{3}\right)$ & $\Delta \mathrm{G}_{\mathrm{C} / \mathrm{ZPVE}}$ \\
\hline Chloroform & -58.49 & -21.36 & -37.13 & 4.8 & -37.39 \\
\hline Ethanol & -50.88 & 8.78 & -59.66 & 6.2 & -60.97 \\
\hline Water & -28.33 & 36.20 & -64.53 & 4.8 & -66.36 \\
\hline
\end{tabular}

Here, the $\left(\triangle \mathrm{G}_{\mathrm{C} / \mathrm{ZPVE}}\right)$ value implies two corrections to solvation energy value, which are corrections by non-electrostatic terms and by ZPVE while with $\left(\Delta \mathrm{G}_{\mathrm{C}}\right)$ is identified to that value only corrected by non-electrostatic terms. The variations of dipole moment, volume, and solvation energy values as functions of permittivity's solvents for C1 and C2 are shown in Figure 2. From Table 1 and Figure $2 \mathrm{a}$, it is observed for both forms the increase of $\mu$ with the permittivity of solvent where clearly the relationships between both properties are non-linear 
and practically follow the same tendency, but the values are higher for $\mathrm{C} 2$. The magnitudes of dipole moment values and vectors for $\mathrm{C} 1$ are different from $\mathrm{C} 2$ in the three solutions, as compared with the corresponding values in the gas phase but practically are constants in the three solutions, as observed in Figure $\mathrm{S} 1$. The changes in the position of the $\mathrm{OH}$ group generate significant variation in the dipole moment vector of $\mathrm{C} 2$.
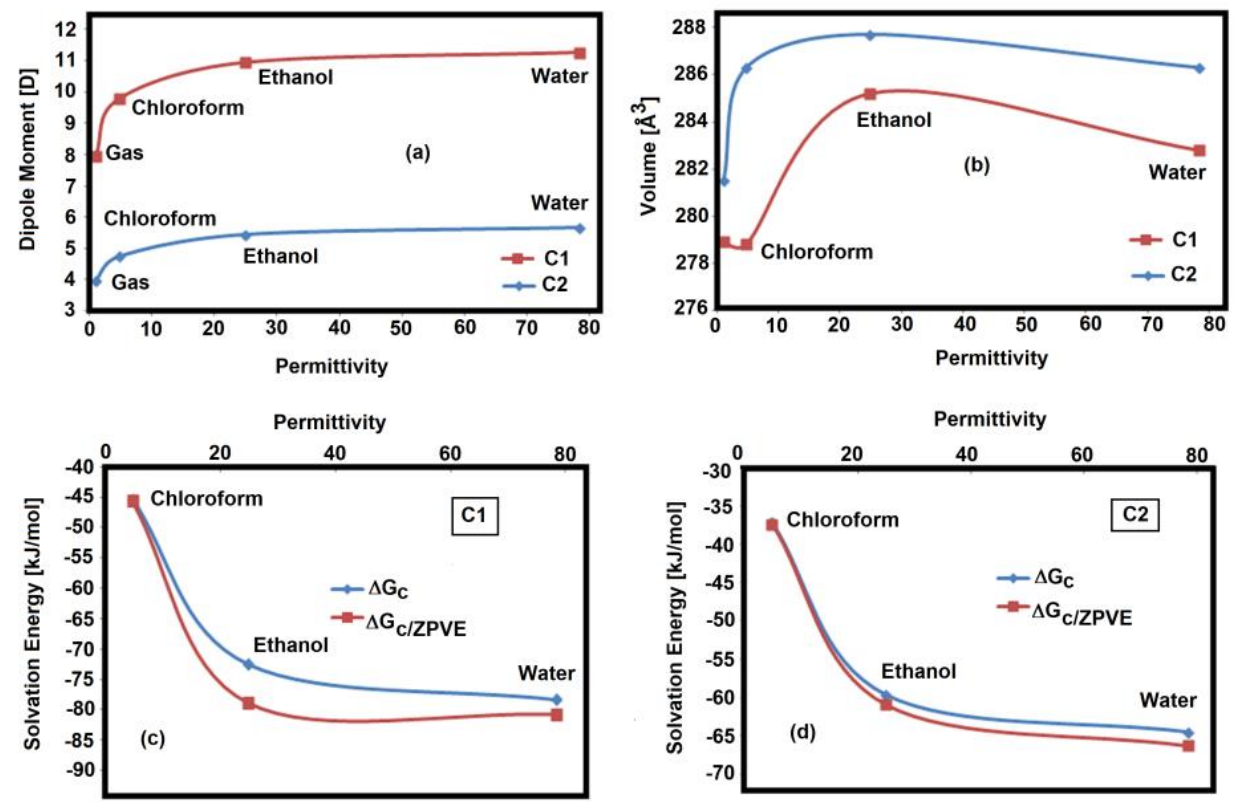

Figure 2. Variations of dipole moment (a) volume (b) and corrected solvation energy values for the two most stable conformers $\mathrm{C} 1$ (c) and C2 (d) of niclosamide as a function of permittivities of solvents.

Concerning volumes, Figure $2 \mathrm{~b}$ shows that the $\mathrm{V}$ values for $\mathrm{C} 1$ and $\mathrm{C} 2$ increase with the permittivity from NCL in the gas phase up to NCL in ethanol solution but, later, the values decrease slightly in water. Note that the $\mathrm{V}$ values in $\mathrm{C} 1$ are higher than the corresponding to $\mathrm{C} 2$. The relationships between $\mathrm{V}$ and $\varepsilon$ values are also non-linear. If now the predicted solvation energies $\left(\Delta \mathrm{G}_{\mathrm{C}}\right)$ are analyzed from Table 2 and Figures $2 \mathrm{c}-2 \mathrm{~d}$ we observed that the values are higher for $\mathrm{C} 1$ and $\mathrm{C} 2$ in water $\left(\Delta \mathrm{GC}=-78.43\right.$ and $\Delta \mathrm{G}_{\mathrm{C} / \mathrm{ZPVE}=}=-80.79$ for $\mathrm{C} 1$ and $\Delta \mathrm{GC}_{\mathrm{C}}=-64.53$ $\mathrm{kJ} / \mathrm{mol}, \Delta \mathrm{G}_{\mathrm{C} / \mathrm{ZPVE}}=-66.36 \mathrm{~kJ} / \mathrm{mol}$ for $\left.\mathrm{C} 2\right)$. Moreover, for both forms, the $\left(\Delta \mathrm{G}_{\mathrm{C} / \mathrm{ZPVE}}\right)$ and $\left(\Delta \mathrm{G}_{\mathrm{C}}\right)$ values decrease with $\varepsilon$, but the values are most negative corrected by ZPVE ( $\left.\Delta \mathrm{G}_{\mathrm{C} / \mathrm{ZPVE}}\right)$. Figures $2 \mathrm{c}-2 \mathrm{~d}$ show few differences between both curves for $\mathrm{C} 1$ and $\mathrm{C} 2$ and where the solvation energies values in chloroform remaining practically constants. At the same time, a slight increase it is observed in ethanol and water (red curve, most negative values).

In this work, the solvation energy $\left(\Delta \mathrm{G}_{\mathrm{C}}\right)$ in aqueous solution were also considered in function of acceptors and donors groups present in both structures of niclosamide because these groups are essential to analyze its oral bioavailability and absorption, as suggested by Veber et al. [60] and Lipinski et al. [61]. Hence, the $\mathrm{H}$ bonds donors (N-H or OH groups) and acceptors ( $\mathrm{N}$ and $\mathrm{O}$ atoms) present in $\mathrm{C} 1$ of NCL structure (because it has higher $\left(\Delta \mathrm{G}_{\mathrm{C}}\right)$ and, other atoms ( $2 \mathrm{Cl}$ atoms) and groups ( $\mathrm{NO}_{2}, 2$ phenyl rings) were compared in Table 3 with solvation energy values reported for other ten antiviral agents in the same medium by using the same level of theory. Thus, the value for the conformer C1 of NCL in water is compared with the corresponding to most stable conformers of chloroquine [9], optimized here with the same method, isothiazol [24], zalcitabine [25], emtricitabine [28], trifluridine [26], thymidine 
[23,29], idoxuridine [27], ribavirin [31], cidofovir and brincidofovir [32] and foscarnet [30]. The structures of all antiviral compounds can be clearly seen in Figure S2.

Table 3. Uncorrected solvation energies by ZPVE energies $\left(\Delta \mathrm{G}_{\mathrm{C}}\right)$ and numbers of $\mathrm{N}-\mathrm{H}$ and $\mathrm{O}-\mathrm{H}$ groups and $\mathrm{N}$ and $\mathrm{O}$ atoms present in ten antiviral species in aqueous solution by using the hybrid B3LYP/6-31G* method.

\begin{tabular}{c|l|c|c|c|c|c|c|c|c|c}
\hline $\mathrm{N}^{\mathrm{o}}$ & \multicolumn{1}{|c|}{ Species } & $\Delta \mathrm{G}_{\mathrm{C}}$ & $\mathrm{N}-\mathrm{H}$ & $\mathrm{O}-\mathrm{H}$ & $\mathrm{O}$ & $\mathrm{C}=\mathrm{O}$ & $\mathrm{N}$ & ToTal & Groups & Rings \\
\hline 1 & Isothiazol $^{\mathrm{b}}$ & -37.51 & 1 & & & & 2 & 3 & $\mathrm{SH}, \mathrm{C} \equiv \mathrm{N}$ & $\mathrm{R} 5, \mathrm{R} 6$ \\
\hline 2 & Chloroquine $^{\mathrm{a}}$ & -52.06 & 1 & & & & 3 & 4 & $\mathrm{Cl}$ & $2 \mathrm{R} 6$ \\
\hline 3 & Niclosamide $^{\mathrm{a}}$ & -78.43 & 1 & 1 & 4 & 1 & 2 & 9 & $2 \mathrm{Cl}, \mathrm{NO}_{2}$ & $2 \mathrm{R}^{2}$ \\
\hline 4 & Zalcitabine $^{\mathrm{c}}$ & -78.92 & $2\left(\mathrm{NH}_{2}\right)$ & 1 & 3 & 1 & 3 & 10 & & $\mathrm{R} 5, \mathrm{R} 6$ \\
\hline 5 & Emtricitabine $^{\mathrm{d}}$ & -100.88 & $2\left(\mathrm{NH}_{2}\right)$ & 1 & 3 & 1 & 3 & 10 & $\mathrm{~F}$ & $\mathrm{R} 5, \mathrm{R} 6$ \\
\hline 6 & Trifluridine $^{\mathrm{e}}$ & -113.85 & 1 & 2 & 5 & 2 & 2 & 12 & $\mathrm{CF}_{3}$ & $\mathrm{R}_{2, \mathrm{R} 6}$ \\
\hline 7 & Thymidine $^{\mathrm{f}}$ & -116.16 & 1 & 2 & 5 & 2 & 2 & 12 & $\mathrm{CH}_{3}$ & $\mathrm{R} 5, \mathrm{R}^{2}$ \\
\hline 8 & Idoxuridine $^{\mathrm{g}, \#}$ & -124.50 & 1 & 2 & 5 & 2 & 2 & 12 & $\mathrm{I}$ & $\mathrm{R} 5, \mathrm{R} 6$ \\
\hline 9 & Ribavirin $^{\mathrm{h}}$ & -141.85 & $2\left(\mathrm{NH}_{2}\right)$ & 3 & 5 & 1 & 4 & 15 & & $2 \mathrm{R} 5$ \\
\hline 10 & Cidofovir $^{\mathrm{i}}$ & -169.21 & $2\left(\mathrm{NH}_{2}\right)$ & 3 & 6 & 1 & 3 & 15 & $\mathrm{H}_{2} \mathrm{PO}_{3}$ & $\mathrm{R} 6$ \\
\hline 11 & Foscarnet $^{\mathrm{j}}$ & -219.64 & & 12 & 5 & 2 & & 19 & $3 \mathrm{Na}$ & \\
\hline 12 & Brincidofovir $^{\mathrm{i}}$ & -227.34 & $2\left(\mathrm{NH}_{2}\right)$ & 2 & 7 & 1 & 3 & 15 & $\mathrm{HPO}_{3}$ & $\mathrm{R} 6$ \\
\hline
\end{tabular}

${ }^{a}$ This work, ${ }^{b}$ From Ref [24], ${ }^{c}$ From Ref [25], ${ }^{d}$ From Ref [28], ${ }^{e}$ From Ref [26], ${ }^{f}$ From Ref [23,29], ${ }^{g}$ From Ref [27], ${ }^{h}$ From Ref [31], ${ }^{i}$ From Ref [32], ${ }^{j}$ From Ref [30]. ${ }^{\#}$ Idoxuridine calculated by using B3LYP/3-21G* calculations.

Note that in the isothiazol structure, 3-mercapto-5-phenyl-4-isothiazolecarbonitrile, there is an $\mathrm{S}-\mathrm{H}$ instead of $\mathrm{N}-\mathrm{H}$ or $\mathrm{OH}$ as the $\mathrm{H}$ bond donor whiles the structures of acid, its trisodic anhydrous and hexahydrated salts are observed for foscarnet. For idoxuridine, the $\Delta \mathrm{G}_{\mathrm{C}}$ values were calculated by using B3LYP/3-21G* $(-124.50 \mathrm{~kJ} / \mathrm{mol})$ and B3LYP/Lanl2dz $(-162.76$ $\mathrm{kJ} / \mathrm{mol})$ calculations. Here, the $\Delta \mathrm{G}_{\mathrm{C}}$ value for idoxuridine $(-124.50 \mathrm{~kJ} / \mathrm{mol})$ with the $\mathrm{B} 3 \mathrm{LYP} / 3-$ 21G* method was considered because it presents a higher energy value (most negative). Note that all compared species have rings in their structures, with the exception of foscarnet because it is a trisodic salt hexahydrated and, for this reason, it drug presents a higher total number of acceptor/donor groups. In foscarnet, each water molecule was also considered as two donor O$\mathrm{H}$ groups. The trisodic salt, foscarnet, has the higher $\Delta \mathrm{G}_{\mathrm{C}}$ value probably due to $\mathrm{B} 3 \mathrm{LYP} / 6-$ $311++\mathrm{G}^{* *}$ method and/or to its cationic form present in aqueous solution. In Figure 3 can be seen the quick increase of $\Delta \mathrm{G}_{\mathrm{c}}$ with the total number of acceptor/donor groups from isothiazol up to foscarnet and then decrease up to brincidofovir. The properties of cidofovir to brincidofovir were previously published in the gas phase [32], but the solvation energy value of brincidofovir in water is here reported for the first time. Both forms of NCL presents only total 9 groups, as compared with the other antiviral agents where we can see that trifluridine [26], thymidine [23,29] and idoxuridine [27] have the same total number of acceptor/donor groups because trifluridine is different from thymidine in $\mathrm{CF}_{3}$ group while idoxuridine has a iodide atom. Moreover, these three antiviral agents have the same five and six member's rings in their structures. Here, $\mathrm{C} 1$ and $\mathrm{C} 2$ in aqueous solution have solvation energy values of $\Delta \mathrm{G}_{\mathrm{C}}=$ -78.43 and $-64.53 \mathrm{~kJ} / \mathrm{mol}$, respectively between those observed for isothiazol $(-37.51 \mathrm{~kJ} / \mathrm{mol})$ and zalcitabine $(-78.92 \mathrm{~kJ} / \mathrm{mol})$. These results show that despite less negative solvation energy values predicted for $\mathrm{C} 1$ and $\mathrm{C} 2$ in aqueous solution, as compared with other antiviral agents, the presence of deactivating groups $\left(\mathrm{NO}_{2}\right.$ and $\left.\mathrm{Cl}\right)$ in the chloro-4-nitrophenyl and hydroxybenzamide rings could explain the higher reactivities observed for NCL in different media. 


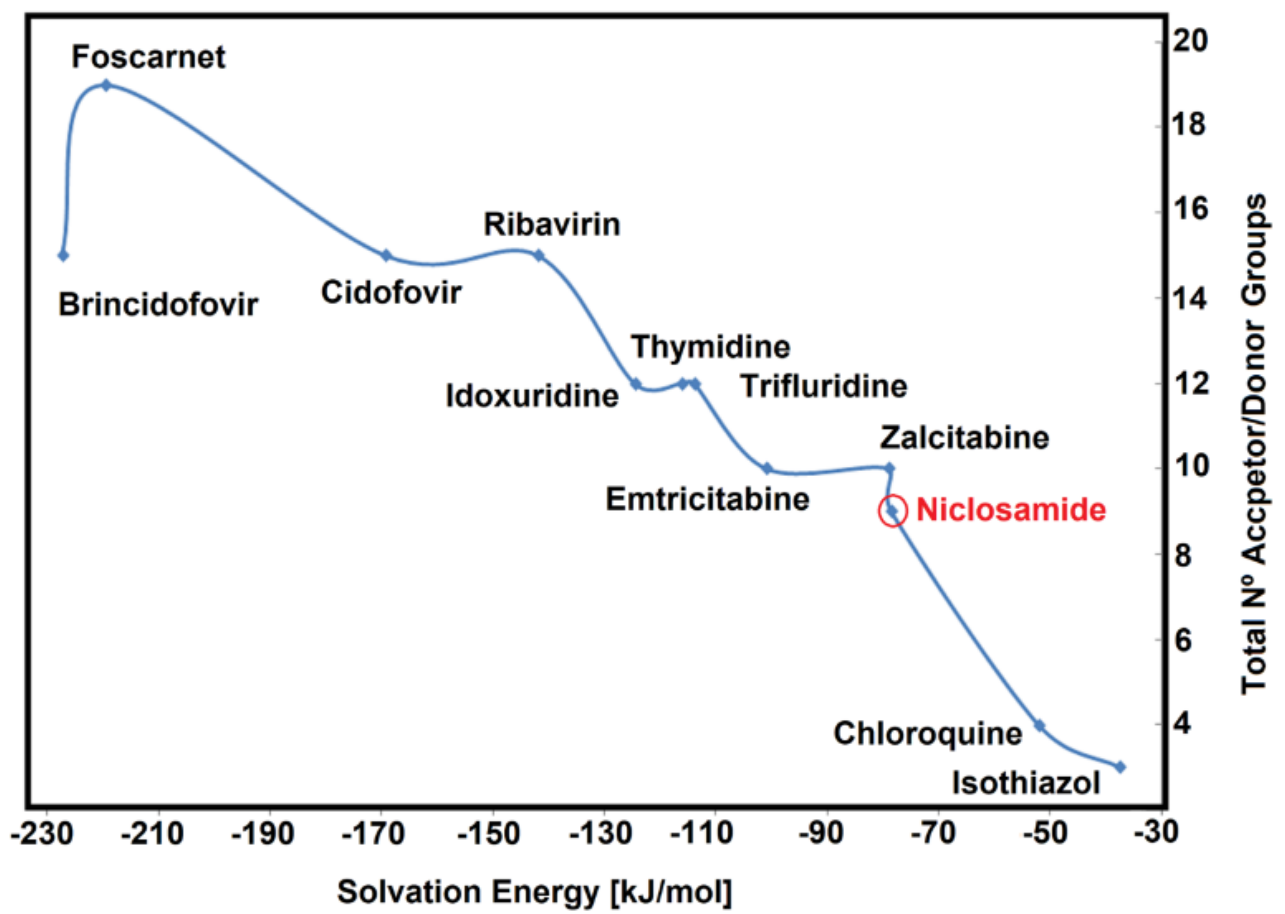

Figure 3. Total number of acceptors and donors groups of eleven antiviral agents as a function of corrected solvation energy values compared with the corresponding to $\mathrm{C} 1$ by using B3LYP/6-31G* level of theory.

\subsection{Geometrical parameters in different media.}

The geometrical parameters calculated for both conformers of NCL in the gas phase and chloroform, ethanol, and water by using the functional hybrid B3LYP with the 6-31G* basis set were compared with the corresponding experimental ones determined for $\mathrm{C} 1$ of $\mathrm{NCL}$ by Sanphui et al. [37] by X-ray diffraction. Comparisons between both experimental and theoretical parameters were carried out with the root-mean-square deviations (RMSD), which are presented in Table 4 for $\mathrm{C} 1$, while in Table S1 are summarized for C2. Analyzing deeply the values for both conformers, a better correlation is observed in bond lengths of $\mathrm{C} 1$, as expected because the experimental structure reported for NCL by Sanphui et al. [37] corresponds to $\mathrm{C} 1$. Hence, the bond lengths values in $\mathrm{C} 1$ are between 0.025 and $0.022 \AA$ while in $\mathrm{C} 2$ between 0.026 and $0.024 \AA$. The differences in the bond angles in $\mathrm{C} 1$ are between 3 and $2.9^{\circ}$ while in $\mathrm{C} 2$, the values are slightly lower $\left(1.9\right.$ and $\left.1.8^{\circ}\right)$. Both forms show higher variations in the dihedral angles. Thus, the dihedral $\mathrm{Cl} 2-\mathrm{C} 20-\mathrm{C} 16-\mathrm{C} 10$ angle for $\mathrm{C} 1$ in the gas phase has a positive value while in the three solutions, change the signs to negative. On the contrary, that dihedral angle in $\mathrm{C} 2$ presents in all media positive values. The dihedral O6-N8C15-C18 angle in $\mathrm{C} 1$ shows negative values in chloroform and ethanol solutions, while this angle presents a negative sign only for $\mathrm{C} 2$ in chloroform solution.

The dihedral $\mathrm{O} 4-\mathrm{C} 11-\mathrm{C} 10-\mathrm{C} 14$ angles for $\mathrm{C} 1$ in ethanol and water have negative values, while for $\mathrm{C} 2$ in all media, the angles show positive values. These changes in the dihedral angles for $\mathrm{C} 1$ and $\mathrm{C} 2$ in the three solutions evidence that better correlations are obtained in the gas phase (2.4-2.1 ${ }^{\circ}$ ) because the presence of acceptors and donor groups $\mathrm{H}$ bonds suggest that these groups are solvated. Therefore, both optimized $\mathrm{C} 1$ and $\mathrm{C} 2$ structures can be used to perform vibrational studies. 
Table 4. Comparison of calculated geometrical parameters for the conformer $\mathrm{C} 1$ of niclosamide in gas and chloroform, ethanol and water solutions compared with the corresponding experimental ones in the solid phase. B3LYP/6-31G*a

\begin{tabular}{|c|c|c|c|c|c|}
\hline Parameters & Gas & Chloroform & Ethanol & Water & $\operatorname{Exp}^{\mathrm{b}}$ \\
\hline \multicolumn{6}{|c|}{ Bond lengths $(\AA)$} \\
\hline C11-O4 & 1.225 & 1.228 & 1.231 & 1.233 & \\
\hline $\mathrm{C} 14-\mathrm{O} 3$ & 1.370 & 1.363 & 1.361 & 1.364 & 1.331 \\
\hline N7-C9 & 1.394 & 1.391 & 1.389 & 1.390 & 1.395 \\
\hline N7-C11 & 1.383 & 1.383 & 1.381 & 1.380 & 1.361 \\
\hline C10-C11 & 1.510 & 1.505 & 1.502 & 1.500 & 1.540 \\
\hline $\mathrm{C} 12-\mathrm{Cl1}$ & 1.761 & 1.761 & 1.760 & 1.759 & 1.730 \\
\hline $\mathrm{C} 20-\mathrm{Cl} 2$ & 1.755 & 1.763 & 1.765 & 1.764 & 1.737 \\
\hline C15-N8 & 1.464 & 1.456 & 1.451 & 1.449 & 1.462 \\
\hline $\mathrm{N} 8-\mathrm{O} 5$ & 1.231 & 1.234 & 1.236 & 1.237 & 1.220 \\
\hline N8-O6 & 1.232 & 1.234 & 1.236 & 1.237 & 1.219 \\
\hline RMSD & 0.022 & 0.023 & 0.024 & 0.025 & \\
\hline \multicolumn{6}{|c|}{ Bond angles $\left({ }^{\circ}\right)$} \\
\hline N7-C11-O4 & 123.1 & 122.8 & 122.6 & 122.5 & \\
\hline N7-C11-C10 & 116.9 & 116.9 & 116.9 & 117.1 & \\
\hline C10-C11-O4 & 119.9 & 120.1 & 120.3 & 120.2 & \\
\hline C10-C14-O3 & 119.0 & 119.0 & 118.9 & 119.0 & \\
\hline C19-C14-O3 & 120.5 & 120.5 & 120.8 & 120.7 & 111.1 \\
\hline C9-N7-C11 & 127.6 & 127.9 & 128.1 & 128.1 & 129.1 \\
\hline C15-N8-O5 & 117.6 & 118.0 & 118.3 & 118.4 & 118.1 \\
\hline C15-N8-O6 & 117.7 & 118.2 & 118.5 & 118.6 & 118.5 \\
\hline O6-N8-O5 & 124.6 & 123.7 & 123.0 & 122.9 & 123.2 \\
\hline N8-C15-C17 & 118.8 & 118.8 & 118.9 & 118.8 & 118.2 \\
\hline N8-C15-C18 & 119.8 & 119.7 & 119.7 & 119.7 & 119.3 \\
\hline $\mathrm{Cl1}-\mathrm{C} 12-\mathrm{C} 9$ & 120.2 & 120.1 & 120.1 & 120.1 & 119.3 \\
\hline Cl1-C12-C17 & 117.8 & 117.7 & 117.7 & 117.7 & 118.0 \\
\hline $\mathrm{Cl2}-\mathrm{C} 20-\mathrm{C} 16$ & 119.8 & 119.5 & 119.5 & 119.5 & 119.5 \\
\hline $\mathrm{Cl} 2-\mathrm{C} 20-\mathrm{C} 21$ & 119.5 & 119.5 & 119.4 & 119.4 & 119.3 \\
\hline RMSD & 2.9 & 2.9 & 3.0 & 2.9 & \\
\hline \multicolumn{6}{|c|}{ Dihedral angles $\left({ }^{\circ}\right)$} \\
\hline C9-N7-C11-O4 & -0.0 & -179.9 & -0.9 & -0.7 & \\
\hline C9-N7-C11-C10 & 179.9 & -0.0 & 178.0 & 178.7 & \\
\hline N7-C9-C12-Cl1 & 0.0 & 0.0 & 0.2 & -0.2 & -3.6 \\
\hline O6-N8-C15-C18 & 179.9 & $\begin{array}{l}-179.9 \\
\end{array}$ & -179.8 & 179.7 & 179.9 \\
\hline N7-Cl1- C10-C14 & -0.0 & -0.0 & 6.6 & 4.0 & \\
\hline C11-C10-C14-O3 & 0.0 & -0.0 & 1.0 & 0.4 & \\
\hline $\mathrm{Cl} 2-\mathrm{C} 20-\mathrm{C} 16-\mathrm{C} 10$ & 180.0 & $\begin{array}{l}-180.0 \\
\end{array}$ & -179.9 & $\begin{array}{l}-179.8 \\
\end{array}$ & 177.8 \\
\hline O4-C11-C10-C14 & 179.9 & 179.9 & -174.3 & -176.3 & \\
\hline RMSD & 2.4 & 293.0 & 292.9 & 206.5 & \\
\hline
\end{tabular}

${ }^{\mathrm{a}}$ This work, ${ }^{\mathrm{b}} \operatorname{Ref}[37]$. 


\subsection{Atomic MK and Mulliken charge, molecular electrostatic potential, and bond orders.}

Atomic charges and the molecular electrostatic potentials in a molecule are useful parameters to describe and explain the different reaction sites and behaviors of species in diverse mediums. In addition to acceptors and donor groups, the presence of two deactivating groups $\left(\mathrm{NO}_{2}\right.$ and $\left.\mathrm{Cl}\right)$ in the chloro-4-nitrophenyl ring and of $\mathrm{Cl}$ atoms in both rings of $\mathrm{C} 1$ and $\mathrm{C} 2$ could easily justify the high reactivities predicted in the different media, as we will see later. Hence, atomic Merz-Kollman (MK) and Mulliken charges, molecular electrostatic potentials (MEP), and bond orders, expressed as Wiberg indexes for $\mathrm{C} 1$ and $\mathrm{C} 2$ in different media by using B3LYP/6-31G* level of theory are presented in Table S2. The behaviors of MK and Mulliken charges on the eight $\mathrm{Cl}, \mathrm{O}$, and $\mathrm{N}$ atoms belonging to $\mathrm{C} 1$ and $\mathrm{C} 2$ in the four media can be seen in Figure S3. The analysis of parameters shows practically the same behaviors of MK and Mulliken charges in the four media and where the MK charges show positive values on all atoms with the exception of N8. On the contrary, Mulliken charges evidence positive values on $\mathrm{Cl1}$ and $\mathrm{N} 8$ atoms of $\mathrm{C} 1$ and $\mathrm{C} 2$ but with null values on $\mathrm{Cl1}$. The lower MK and Mulliken charge values for $\mathrm{C} 1$ and $\mathrm{C} 2$ are observed on the $\mathrm{O} 3$ and $\mathrm{N} 7$ atoms, probably due to that these atoms are involved in the $\mathrm{H}$ bonds formations. In $\mathrm{C} 1$, the two $\mathrm{C} 11-\mathrm{O} 4 \cdots \mathrm{H} 23$ and N7$\mathrm{H} 22 \cdots \mathrm{O} 3$ bonds are formed while, in $\mathrm{C} 2$, four $\mathrm{H}$ bonds are formed $(\mathrm{C} 11-\mathrm{O} 4 \cdots \mathrm{H} 23$, O3$\mathrm{H} 29 \cdots \mathrm{O} 4, \mathrm{C} 12-\mathrm{Cl} 1 \cdots \mathrm{H} 22$ and $\mathrm{N} 7-\mathrm{H} 22 \cdots \mathrm{H} 24$ bonds).Therefore, $\mathrm{C} 2$ is most stable than $\mathrm{C} 1$, as was previously analyzed.

Regarding the molecular electrostatic potentials, the values on the eight considered atoms are approximately the same in the four media, as observed in Table S2. However, when the mapped MEP surfaces are graphed in Figure S4, different colorations for both forms are found. Thus, in $\mathrm{C} 2$ strong red colors are observed on the $\mathrm{O}$ atoms of $\mathrm{NO}_{2}, \mathrm{C}=\mathrm{O}$, and $\mathrm{OH}$ groups while the colorations on the $\mathrm{NO}_{2}$ and $\mathrm{C}=\mathrm{O}$ groups are weak in $\mathrm{C} 1$. This fact could be explained taking into account the four $\mathrm{H}$ bonds in $\mathrm{C} 2$, for which, the $\mathrm{R} 1$ ring is less deactivate because the $\mathrm{Cl} 1$ atom is forming the $\mathrm{C} 12-\mathrm{Cl} 1 \cdots \mathrm{H} 22$ bond while in $\mathrm{C} 1$ the $\mathrm{Cl} 1$ atoms are not involved in a $\mathrm{H}$ bond. On the other hand, the strong blue color in $\mathrm{C} 2$ is observed on the $\mathrm{N} 7-\mathrm{H} 22$ bond while in $\mathrm{C} 1$ is observed on the $\mathrm{O} 3-\mathrm{H} 29$ bond and in this form that $\mathrm{NH}$ bond is involved in the formation of $\mathrm{N} 7-\mathrm{H} 22 \cdots \mathrm{O} 3$ bond. Then, the nucleophilic and electrophilic sites can be identified respectively with red and blue colors, while neutral or inert regions are identified by green colors. Here, the strong red and blue colorations observed for $\mathrm{C} 2$ could be associated with the higher reactivity predicted for this form, as compared with the $\mathrm{C} 1$ form.

In addition, for $\mathrm{C} 1$ and $\mathrm{C} 2$, bond orders (BO) expressed as Wiberg indexes were also calculated due to the presence of deactivating and acceptors and donors groups in its structures. Accordingly, in Table S2, the BO of those eight atoms of C1 and C2 calculated in the four media by using the B3LYP/6-31G* level of theory are presented. The careful analysis of data shows that the $\mathrm{BO}$ values for the different atoms follow the tendency $\mathrm{N}>\mathrm{O}>\mathrm{Cl}$. Thus, the $\mathrm{Cl}$ and $\mathrm{O}$ atoms have approximately the same values in both forms and in the four media, but the $\mathrm{N} 8$ atoms have higher values than those observed for the N7 atoms, as expected because the $\mathrm{N} 8$ atoms belong to the $\mathrm{NO}_{2}$ groups and they are linked to $\mathrm{O}$ atoms. Here, the $\mathrm{BO}$ values do not any show significant differences between both conformers in the four media.

\subsection{NBO and AIM studies.}

Due to the presence of acceptors and donors groups, of two deactivating groups $\left(\mathrm{NO}_{2}\right.$ and $\mathrm{Cl}$ ) in the chloro-4-nitrophenyl ring and $\mathrm{Cl}$ atoms in both rings of $\mathrm{C} 1$ and $\mathrm{C} 2$, calculations 
of Second-Order Perturbation Theory Analysis of Fock Matrix in NBO Basis by using NBO analysis and of topological properties by using Bader's theory of atoms in molecules (AIM) are valuable tools necessaries to investigate the existence of different interaction's types, such as $\mathrm{H}$ bonds or inter and intra-molecular interactions [45-48]. Hence, acceptor-donors energies and topological properties were predicted for $\mathrm{C} 1$ and $\mathrm{C} 2$ of NCL in the four media by using the versions 3.1 and 2000 of NBO and AIM programs, respectively [46,47]. Thus, the main delocalization energies for $\mathrm{C} 1$ and $\mathrm{C} 2$ in the gas phase, chloroform, ethanol, and water solutions by using the B3LYP with the 6-31G* basis set are presented in Tables S3 and S4, respectively. The exhaustive analysis of results show that $\mathrm{C} 1$ presents five different interactions $\left(\Delta E_{\pi \rightarrow \pi^{*}}\right.$, $\Delta E_{\pi \rightarrow n}, \Delta E_{n \rightarrow \pi^{*}}, \Delta E_{n \rightarrow \sigma^{*}}$ and $\left.\Delta E_{\pi^{*} \rightarrow \pi^{*}}\right)$ while for $\mathrm{C} 2$ in the different media are observed seven interactions $\left(\Delta E_{\pi \rightarrow \pi^{*}}, \Delta E_{\pi \rightarrow n}, \Delta E_{\pi \rightarrow n^{*}}, \Delta E_{n \rightarrow \pi^{*}}, \Delta E_{n \rightarrow \sigma^{*}}, \Delta E_{n \rightarrow n^{*}}\right.$ and $\Delta E_{\pi^{*} \rightarrow \pi^{*}}$ ). On the other hand, due to the different positions of $\mathrm{O} 3-\mathrm{H} 29$ group in $\mathrm{C} 1$ and $\mathrm{C} 2$ two new $\Delta E_{\pi \rightarrow n^{*}}$ and $\Delta E_{n \rightarrow n^{*}}$ interactions are observed in $\mathrm{C} 2$ different from $\mathrm{C} 1$. Besides, the $\Delta E_{\pi \rightarrow \pi^{*}}$ and $\Delta E_{\pi^{*} \rightarrow \pi^{*}}$ transitions in $\mathrm{C} 1$ present higher values than those observed in $\mathrm{C} 2$ while, on the contrary, the predicted $\Delta E_{n \rightarrow \pi^{*}}$ transitions in $\mathrm{C} 2$ is higher than $\mathrm{C} 1$. A very important resulted is observed in the same values of $\Delta E_{n \rightarrow \sigma^{*}}$ transitions related to the lone pairs of $\mathrm{O} 4, \mathrm{O} 5$, and $\mathrm{O} 6$ atoms of both conformers $(504.67 / 504.59 \mathrm{~kJ} / \mathrm{mol})$. Probably, such observation can be explained because the positions of these atoms in chloro-4-nitrophenyl rings and $\mathrm{C}=\mathrm{O}$ groups in both conformers present the same positions in both forms. In contrast, the other hydroxybenzamide rings are different in $\mathrm{C} 1$ and $\mathrm{C} 2$. This NBO study clearly shows the higher stability of $\mathrm{C} 1$ than $\mathrm{C} 2$.

According to Bader's theory of atoms in molecules (AIM), the topological properties were computed for $\mathrm{C} 1$ and $\mathrm{C} 2$ in the four media by using the AIM2000 program in order to investigate $\mathrm{H}$ bonds or inter and intra-molecular interactions $[47,48]$. Thus, the electron density, $\rho(r)$, the Laplacian values, $\nabla^{2} \rho(r)$, the eigenvalues $(\lambda 1, \lambda 2, \lambda 3)$ of the Hessian matrix and the $\lambda 1 / \lambda 3$ ratios were calculated for $\mathrm{C} 1$ and $\mathrm{C} 2$ in the bond critical points (BCPs) and the ring critical points (RCPs) by using the B3LYP/6-31G* method. Here, it is necessary to remember that the $\mathrm{H}$ bond interactions present a ratio of $\lambda 1 / \lambda 3<1$ and $\nabla^{2} \rho(r)>0$. Those topological properties for $\mathrm{C} 1$ and $\mathrm{C} 2$ in the different media can be seen in Tables S5 and S6 together with the distances between the involved atoms. In $\mathrm{C} 1$, three new BCPs are predicted, which are the $\mathrm{C} 11-\mathrm{O} 4 \cdots \mathrm{H} 23, \mathrm{C} 11-\mathrm{O} 4 \cdots \mathrm{H} 23$ and $\mathrm{C} 12-\mathrm{C} 11 \cdots \mathrm{H} 22$ interactions and, for these reasons, three new RCPs appear (RCPN1, RCPN2 and RCPN3) while in C2, four new

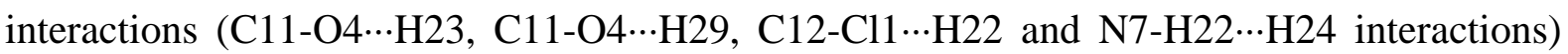
and four new RCPs are observed (RCPN1, RCPN2 and RCPN3). Besides, in both forms are present the RCPs of both chloro-4-nitrophenyl and hydroxybenzamide rings (RCP1 and $\mathrm{RCP} 2$ ). All interactions of conformers $\mathrm{C} 1$ and $\mathrm{C} 2$ in the gas phase showing the geometry of all their BCPs and RCPs can be easily seen in the molecular graphics presented in Figure S5. These AIM studies show the high theoretical stability of C2.

\subsection{Frontier orbitals and global descriptors studies.}

The frontier orbital studies are very important in C1 and C 2 of NCL because a recent study performed by $\mathrm{Xu}$ et al. [12] suggest to NCL as a potential antiviral agent due to its effectivity against various viral infections such as SARS-CoV, MERS-CoV, ZIKV, HCV, and human adenovirus. Hence, the reactivities of both forms are here predicted by using the differences between the HOMO and LUMO named gap, as recommended by Parr and Pearson [49]. Then, with the gap values the chemical potential $(\chi)$, electronegativity $(\mu)$, hardness $(\eta)$, 
softness $(S)$, global electrophilicity index $(\omega)$ and global nucleophilicity index $(E)$ descriptors are also calculated with known equations [50-56]. Then, all these properties for $\mathrm{C} 1$ and $\mathrm{C} 2$ in the gas phase, chloroform, ethanol, and aqueous solutions by using the hybrid B3LYP level of theory are presented in Table 5 together with the corresponding equations. $\mathrm{C} 1$ shows higher values in all media, as compared with $\mathrm{C} 2$, while slight reductions in gap values are observed for both forms in the different media when increasing the permittivities of solvents. Later, both conformations evidence higher reactivities in water.

Table 5. Calculated chemical potential $(\mu)$, electronegativity $(\chi)$, global hardness $(\eta)$, global softness $(S)$, global electrophilicity index $(\omega)$ and global nucleophilicity index $(E)$ for conformers $\mathrm{C} 1$ and $\mathrm{C} 2$ of antiviral niclosamide by using the hybrid B3LYP level of theory.

\begin{tabular}{|c|c|c|c|c|}
\hline \multicolumn{5}{|c|}{ B3LYP/6-31G* } \\
\hline \multicolumn{5}{|c|}{ Conformer C1 } \\
\hline Orbitals & Gas & Chloroform & Ethanol & Water \\
\hline HOMO & -6.7457 & -6.7484 & -6.7511 & -6.7566 \\
\hline LUMO & -2.5252 & -2.5524 & -2.5715 & -2.5824 \\
\hline GAP & 4.2205 & 4.1960 & 4.1796 & 4.1742 \\
\hline \multicolumn{5}{|c|}{ DESCRIPTORS } \\
\hline$\chi$ & -2.1103 & -2.0980 & -2.0898 & -2.0871 \\
\hline$\mu$ & -4.6355 & -4.6504 & -4.6613 & -4.6695 \\
\hline$\eta$ & 2.1103 & 2.0980 & 2.0898 & 2.0871 \\
\hline$S$ & 0.2369 & 0.2383 & 0.2393 & 0.2396 \\
\hline$\omega$ & 5.0912 & 5.1540 & 5.1985 & 5.2236 \\
\hline$E$ & -9.7820 & -9.7565 & -9.7412 & -9.7457 \\
\hline \multicolumn{5}{|c|}{ Conformer $\mathrm{C} 2$} \\
\hline Orbitals & Gas & Chloroform & Ethanol & Water \\
\hline HOMO & -6.5471 & -6.5552 & -6.5688 & -6.5797 \\
\hline LUMO & -2.7864 & -2.8218 & -2.8436 & -2.8572 \\
\hline GAP & 3.7607 & 3.7334 & 3.7252 & 3.7225 \\
\hline \multicolumn{5}{|c|}{ DESCRIPTORS } \\
\hline$\chi$ & -1.8804 & -1.8667 & -1.8626 & -1.8613 \\
\hline$\mu$ & -4.6668 & -4.6885 & -4.7062 & -4.7185 \\
\hline$\eta$ & 1.8804 & 1.8667 & 1.8626 & 1.8613 \\
\hline$S$ & 0.2659 & 0.2679 & 0.2684 & 0.2686 \\
\hline$\omega$ & 5.7911 & 5.8879 & 5.9455 & 5.9809 \\
\hline $\mathrm{E}$ & -8.7751 & -8.7520 & -8.7658 & -8.7822 \\
\hline
\end{tabular}

$\chi=-[E(L U M O)-E(H O M O)] / 2 ; \mu=[E(L U M O)+E(H O M O)] / 2 ; \eta=[E(L U M O)-E(H O M O)] / 2 ; S=1 / 2 \eta ; \omega=\mu^{2} / 2 \eta ; E=\mu * \eta$

When the global electrophilicity index $(\omega)$ and global nucleophilicity index $(E)$ are analyzed we observed that the low reactivities that evidence both forms could be attributed to the high values of $(\omega)$ and most negative values of $(E)$. Then, these properties for $\mathrm{C} 1$ and $\mathrm{C} 2$ of NCL are compared with those reported for antiviral chloroquine, isothiazol [24], zalcitabine [25], emtricitabine [28], trifluridine [26], thymidine [23,29], idoxuridine [27], ribavirin [31], cidofovir and brincidofovir [32] and foscarnet agents [30] in Table 6 at different levels of theory. When the values are deeply analyzed, quickly it is observed that $\mathrm{C} 2$ in all media presents slightly lower values (3.7601-3.7225 eV) and higher reactivity than brincidofovir $(3.7715 \mathrm{eV})$, the antiviral agent used in the treatment to Ebola disease. In comparison, the values of $\mathrm{C} 1$ are slightly higher (4.2205-4.1742 eV). Hence, C2 of NCL is the most reactive antiviral agent than those eleven compared antiviral ones. 
Table 6. Frontier molecular HOMO and LUMO orbitals, gap and chemical potential $(\mu)$, electronegativity $(\chi)$, global hardness $(\eta)$, global softness $(S)$, global electrophilicity index $(\omega)$ and global nucleophilicity index $(E)$ for antiviral agents calculated at different levels of theory by using the functional hybrid B3LYP.

\begin{tabular}{|c|c|c|c|c|c|c|}
\hline \multirow{3}{*}{$\begin{array}{l}\text { Frontier orbitals } \\
\qquad(\mathrm{eV})\end{array}$} & \multicolumn{6}{|c|}{ B3LYP Method } \\
\hline & \multicolumn{4}{|c|}{$6-31 G^{*}$} & \multirow{2}{*}{$\begin{array}{c}3-21 \mathrm{G}^{*} \\
\text { Trifluridine }^{\mathrm{e}}\end{array}$} & \multirow{2}{*}{$\frac{6-31 G^{*}}{\text { Thymidine }^{f}}$} \\
\hline & Chloroquine $^{\mathrm{a}}$ & Isothiazol $^{\mathrm{b}}$ & Zalcitabine $^{c}$ & Emtricitabine $^{\mathrm{d}}$ & & \\
\hline HOMO & -5.5708 & -6.692 & -6.1138 & -6.1825 & -6.8882 & -6.1061 \\
\hline LUMO & -1.1137 & -2.185 & -0.7543 & -1.0629 & -1.3006 & -0.6313 \\
\hline$|\mathrm{GAP}|$ & 4.4571 & 4.507 & 5.3595 & 4.9336 & 5.5876 & 5.4748 \\
\hline \multicolumn{7}{|c|}{ DESCRIPTORS } \\
\hline$\chi$ & -2.2286 & -2.2535 & -2.6798 & -2.5598 & -2.7938 & -2.7374 \\
\hline$\mu$ & -3.3423 & -4.4385 & -3.4341 & -3.6227 & -4.0944 & -3.3687 \\
\hline$\eta$ & 2.2286 & 2.2535 & 2.6798 & 2.5598 & 2.7938 & 2.7374 \\
\hline$S$ & 0.2244 & 0.2219 & 0.1866 & 0.1953 & 0.1790 & 0.1827 \\
\hline$\omega$ & 2.5063 & 4.3710 & 2.2003 & 2.5635 & 3.0002 & 2.0728 \\
\hline $\mathrm{E}$ & -7.4484 & -10.0022 & -9.2024 & -9.2734 & -11.4389 & -9.2215 \\
\hline \multicolumn{7}{|c|}{ B3LYP Method } \\
\hline & \multicolumn{3}{|c|}{ 6-31G* } & $6-311++\mathrm{G}^{* *}$ & 6-31G* & \\
\hline Frontier orbitals & Idoxuridine $^{\mathrm{g}, \#}$ & Ribavirin $^{\mathrm{h}}$ & Cidofovir $^{\mathrm{i}}$ & Foscarnet $^{j}$ & Brincidofovir $^{\mathrm{i}}$ & \\
\hline HOMO & -6.2600 & -6.7958 & -5.9366 & -6.9135 & -5.5435 & \\
\hline LUMO & -1.2438 & -0.9530 & -0.6401 & -0.6413 & -1.772 & \\
\hline$|\mathrm{GAP}|$ & 5.0162 & 5.8428 & 5.2965 & 6.2722 & 3.7715 & \\
\hline \multicolumn{7}{|c|}{ DESCRIPTORS } \\
\hline$\chi$ & -2.5081 & -2.9214 & -2.6483 & -3.1361 & -1.8858 & \\
\hline$\mu$ & -3.7519 & -3.8744 & -3.2884 & -3.7774 & -3.6578 & \\
\hline$\eta$ & 2.5081 & 2.9214 & 2.6483 & 3.1361 & 1.8858 & \\
\hline$S$ & 0.1994 & 0.1712 & 0.1888 & 0.1594 & 0.2651 & \\
\hline$\omega$ & 2.8063 & 2.5691 & 2.0416 & 2.2749 & 3.5474 & \\
\hline $\bar{E}$ & -9.4101 & -11.3187 & -8.7084 & -11.8463 & -6.8976 & \\
\hline
\end{tabular}

aThis work, ${ }^{\mathrm{b}}$ From Ref [24], ${ }^{\mathrm{c}}$ From Ref [25], ${ }^{\mathrm{d}}$ From Ref [28], ${ }^{\mathrm{e}}$ From Ref [26], ${ }_{\mathrm{f}}^{\mathrm{f}}$ From Ref [23,29], ${ }^{\mathrm{g}}$ From Ref [27], ${ }^{\mathrm{h}}$ From Ref

[31], ${ }^{\mathrm{i}}$ From Ref [32], ${ }^{\text {FFrom Ref [30]. }}{ }^{\#}$ Idoxuridine calculated by using B3LYP/3-21G* calculations. $\chi=-$ [E(LUMO)-

$\mathrm{E}(\mathrm{HOMO})] / 2 ; \mu=[\mathrm{E}(\mathrm{LUMO})+\mathrm{E}(\mathrm{HOMO})] / 2 ; \eta=[\mathrm{E}(\mathrm{LUMO})-\mathrm{E}(\mathrm{HOMO})] / 2 ; S=1 / 2 \eta ; \omega=\mu^{2} / 2 \eta ; \mathrm{E}=\mu * \eta$

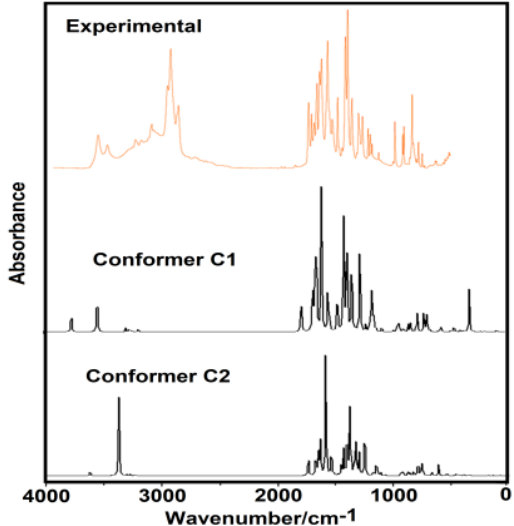

Figure 4. Experimental ATR spectrum of niclosamide (5-Chloro-N-(2-chloro-4-nitrophenyl)-2hydroxybenzamide) in mull of Nujol compared with the corresponding predicted for $\mathrm{C} 1$ and $\mathrm{C} 2$ in the gas phase by using B3LYP/6-31G* level of theory.

\subsection{Vibrational study.}

These vibrational studies are essential to identify both forms of NCL in all media by using the infrared and Raman spectra. The hybrid B3LYP/6-31G* calculations have optimized

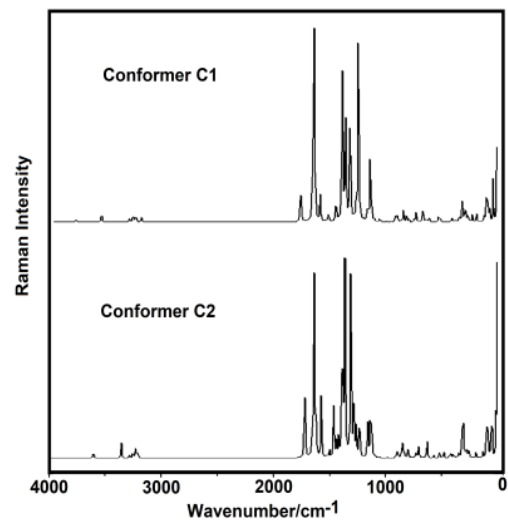

Figure 5. Predicted Raman spectrum for $\mathrm{C} 1$ and $\mathrm{C} 2$ of niclosamide (5-Chloro-N-(2-chloro-4nitrophenyl)-2-hydroxybenzamide) in the gas phase by using B3LYP/6-31G* level of theory. 
the structures of $\mathrm{C} 1$ and $\mathrm{C} 2$ in all media with $C_{1}$ symmetries and only, 81 normal vibration modes with activities in both spectra are expected for both forms. Figure 4 shows the experimental available ATR spectrum of niclosamide in mull Nujol was taken from Ref [62] compared with that corresponding predicted for both forms in the gas phase by using the B3LYP/6-31G* method. Figure 5 are presented the predicted Raman spectra for both forms in the gas phase by using the same method.

For a better correlation, the theoretical Raman spectra in activities were transformed into intensities by using the corrections suggested in the literature [63,64]. Note that the group of IR bands intense and media intensities between 2954 and $2853 \mathrm{~cm}^{-1}$ and the strong IR band at $751 \mathrm{~cm}^{-1}$ are clearly assigned to nujol because it is hydrocarbon oil that absorbs in these regions.

The intense band predicted in the IR spectrum of $\mathrm{C} 2$ in the higher wavenumbers region, not observed in the experimental one, confirm that the form $\mathrm{C} 1$ is present in the solid phase, as experimentally was determined by Sanphui et al. [37] by using X-ray diffraction. The difference observed between experimental and theoretical spectra can be attributed to the calculations because these were performed in the gas phase, where the packing forces were not considered. Here, the harmonic force fields and the corresponding vibrational assignments for both forms of NCL were computed by using the SQMFF methodology, the normal internal coordinates, transferable scaling factors, and the Molvib program [34-36]. The experimental and calculated wavenumbers for both conformers $\mathrm{C} 1$ and $\mathrm{C} 2$ of NCL in gas phase are summarized in Table 7 by using the functional hybrid B3LYP with the 6-31G* basis set. Discussions only for some groups are presented below for the most important regions.

\subsubsection{Band Assignments.}

4000-2000 $\mathrm{cm}^{-1}$ Region. In this region, for $\mathrm{C} 1$ and $\mathrm{C} 2$ are expected the six $\mathrm{C}-\mathrm{H}$ and the $\mathrm{N}-\mathrm{H}$ and $\mathrm{O}-\mathrm{H}$ stretching modes corresponding to chloro-4-nitrophenyl and hydroxybenzamide rings, which are predicted between 3605 and $3047 \mathrm{~cm}^{-1}$. Hence, the weak IR bands at 3581 and $3498 \mathrm{~cm}^{-1}$ are assigned to the $\mathrm{O}-\mathrm{H}$ and $\mathrm{N}-\mathrm{H}$ stretching modes, respectively [23-32,50-56]. Then, the six C-H stretching modes are associated with the IR bands located between 3197 and $3079 \mathrm{~cm}^{-1}$.

Table 7. Observed and calculated wavenumbers $\left(\mathrm{cm}^{-1}\right)$ and assignments for conformers $\mathrm{C} 1$ and $\mathrm{C} 2$ of antiviral niclosamide in the gas phase by using the hybrid B3LYP level of theory.

\begin{tabular}{|c|c|c|c|c|}
\hline \multirow{3}{*}{$\begin{array}{c}\text { Experimental }^{\mathbf{d}} \\
\text { ATR }^{\mathrm{c}}\end{array}$} & \multicolumn{4}{|c|}{ B3LYP/6-31G* Method ${ }^{\mathrm{a}}$} \\
\hline & \multicolumn{2}{|r|}{ C1 } & \multicolumn{2}{|r|}{$\mathrm{C2}$} \\
\hline & $\mathbf{S Q M}^{\mathbf{b}}$ & Assignments & $\mathbf{S Q M}^{\mathbf{b}}$ & Assignments \\
\hline $3581 w$ & 3605 & vO3-H29 & & \\
\hline \multirow[t]{2}{*}{$3498 w$} & 3390 & vN7-H22 & 3459 & $v \mathrm{~N} 7-\mathrm{H} 22$ \\
\hline & & & 3222 & vO3-H29 \\
\hline $3197 w$ & 3154 & vC13-H23 & 3153 & vC13-H23 \\
\hline $3122 \mathrm{sh}$ & 3128 & $v \mathrm{C} 17-\mathrm{H} 25$ & 3128 & vC17-H25 \\
\hline $3122 \mathrm{sh}$ & 3119 & vC18-H26 & 3121 & $v \mathrm{C} 18-\mathrm{H} 26$ \\
\hline $3097 \mathrm{~m}$ & 3114 & vC16-H24 & 3098 & vC19-H27 \\
\hline $3079 w$ & 3096 & vC19-H27 & 3086 & vC21-H28 \\
\hline $3079 w$ & 3047 & $v \mathrm{C} 21-\mathrm{H} 28$ & 3076 & vC16-H24 \\
\hline $1686 \mathrm{~m}$ & 1707 & $\mathrm{vC11}=\mathrm{O} 4$ & 1672 & $v \mathrm{C} 11=\mathrm{O} 4$ \\
\hline $1657 \mathrm{~m}$ & 1619 & $\rho \mathrm{N} 7-\mathrm{H} 22$ & 1615 & $v_{\mathrm{a} N O}, \rho \mathrm{N} 7-\mathrm{H} 22$ \\
\hline $1632 \mathrm{~m}$ & 1600 & $\nu \mathrm{C} 14-\mathrm{C} 19, \mathrm{vC} 20-\mathrm{C} 16$ & 1606 & $v \mathrm{C} 20-\mathrm{C} 16$ \\
\hline $1607 \mathrm{~s}$ & 1591 & $\mathrm{v}_{\mathrm{a}} \mathrm{NO}_{2}$ & 1588 & $v \mathrm{C} 13-\mathrm{C} 18$ \\
\hline $1582 \mathrm{~s}$ & 1589 & vC13-C18 & 1582 & $v_{\mathrm{aNO}}, \rho \mathrm{N} 7-\mathrm{H} 22$ \\
\hline
\end{tabular}




\begin{tabular}{|c|c|c|c|c|}
\hline \multirow{3}{*}{$\begin{array}{c}\text { Experimental }^{\mathrm{d}} \\
\text { ATR }^{\mathrm{c}} \\
\end{array}$} & \multicolumn{4}{|c|}{ 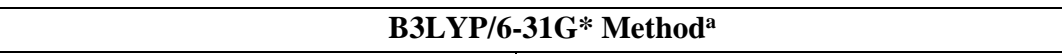 } \\
\hline & \multicolumn{2}{|r|}{ C1 } & \multicolumn{2}{|r|}{$\mathbf{C 2}$} \\
\hline & $\mathbf{S Q M}^{\mathbf{b}}$ & Assignments & $\mathbf{S Q M}^{\mathbf{b}}$ & Assignments \\
\hline $1567 \mathrm{~s}$ & 1581 & vC10-C14,vC19-C21 & 1568 & $v \mathrm{C} 10-\mathrm{C} 14, \mathrm{vC} 19-\mathrm{C} 21$ \\
\hline $1514 \mathrm{~s}$ & 1535 & $v \mathrm{C} 15-\mathrm{C} 18$ & 1533 & $v \mathrm{C} 15-\mathrm{C} 18$ \\
\hline $1470 \mathrm{~m}$ & 1482 & $\beta \mathrm{C} 16-\mathrm{H} 24$ & 1480 & $\beta \mathrm{C} 19-\mathrm{H} 27$ \\
\hline $1424 \mathrm{~m}$ & 1468 & $v \mathrm{C} 15-\mathrm{C} 17, v \mathrm{C} 9-\mathrm{C} 12$ & 1462 & $v \mathrm{C} 15-\mathrm{C} 17$ \\
\hline $1381 w$ & 1403 & $v \mathrm{C} 10-\mathrm{C} 16$ & 1414 & $v \mathrm{C} 10-\mathrm{C} 16, v \mathrm{C} 20-\mathrm{C} 16$ \\
\hline $1352 \mathrm{~s}$ & 1399 & $\mathrm{vC} 12-\mathrm{C} 17$ & 1399 & $v \mathrm{C} 12-\mathrm{C} 17$ \\
\hline 1331vs & 1346 & $\mathrm{v}_{\mathrm{s}} \mathrm{NO}_{2}$ & 1366 & $\delta \mathrm{OH}$ \\
\hline 1331vs & 1316 & vC9-C13 & 1348 & $v_{\mathrm{s}} \mathrm{NO}_{2}$ \\
\hline 1331vs & 1310 & $v \mathrm{C} 20-\mathrm{C} 16$ & 1323 & vC9-C13 \\
\hline $1295 \mathrm{~m}$ & 1282 & $\mathrm{vC14-O3}$ & 1312 & $\mathrm{vC14-O3}$ \\
\hline $1295 \mathrm{~m}$ & 1280 & vC9-N7 & 1290 & $\mathrm{vC14-O3}$ \\
\hline $1231 \mathrm{~m}$ & 1251 & $\beta \mathrm{C} 17-\mathrm{H} 25, \beta \mathrm{C} 13-\mathrm{H} 23$ & 1276 & $\nu \mathrm{C} 9-\mathrm{N} 7, \beta \mathrm{C} 13-\mathrm{H} 23, \nu \mathrm{C} 9-\mathrm{C} 12$ \\
\hline $1231 \mathrm{~m}$ & 1234 & $\beta \mathrm{C} 17-\mathrm{H} 25$ & 1250 & $v \mathrm{C} 10-\mathrm{C} 16, \beta \mathrm{C} 16-\mathrm{H} 24, v \mathrm{C} 10-\mathrm{C} 11$ \\
\hline $1198 \mathrm{~m}$ & 1210 & vC10-C11 & 1235 & $\beta \mathrm{C} 17-\mathrm{H} 25$ \\
\hline $1144 w$ & 1156 & $\beta C 19-\mathrm{H} 27, \beta \mathrm{C} 21-\mathrm{H} 28$ & 1199 & vC14-C19 \\
\hline $1130 \mathrm{w}$ & 1137 & $\beta \mathrm{C} 18-\mathrm{H} 26$ & 1139 & $\beta \mathrm{C} 18-\mathrm{H} 26$ \\
\hline $1116 \mathrm{w}$ & 1114 & $\delta \mathrm{OH}, v \mathrm{C} 11-\mathrm{N} 7$ & 1133 & $\beta \mathrm{C} 21-\mathrm{H} 28$ \\
\hline \multirow[t]{2}{*}{$1112 w$} & 1110 & vC15-N8 & 1109 & vC15-N8 \\
\hline & 1093 & $\beta \mathrm{R}_{1}(\mathrm{~A} 1)$ & 1092 & $\beta \mathrm{R}_{1}(\mathrm{~A} 1), v \mathrm{C} 20-\mathrm{C} 21$ \\
\hline \multirow[t]{4}{*}{$1051 \mathrm{w}$} & 1077 & $\mathrm{vC} 20-\mathrm{C} 21$ & 1073 & $\mathrm{vC11-N7}$ \\
\hline & 1038 & $\beta \mathrm{R}_{1}(\mathrm{~A} 2)$ & 1038 & $\beta \mathrm{R}_{1}(\mathrm{~A} 2)$ \\
\hline & 992 & $\gamma \mathrm{C} 18-\mathrm{H} 26$ & 988 & $\gamma \mathrm{C} 18-\mathrm{H} 26$ \\
\hline & 949 & $\gamma \mathrm{C} 16-\mathrm{H} 24$ & 963 & $\gamma \mathrm{C} 21-\mathrm{H} 28$ \\
\hline $919 \mathrm{w}$ & 924 & $\gamma \mathrm{C} 21-\mathrm{H} 28$ & 917 & $\gamma \mathrm{C} 17-\mathrm{H} 25$ \\
\hline $919 w$ & 916 & $\gamma \mathrm{C} 17-\mathrm{H} 25$ & 914 & $\delta \mathrm{C} 9 \mathrm{~N} 7 \mathrm{C} 11$ \\
\hline $908 \mathrm{~m}$ & 911 & $\delta \mathrm{C} 9 \mathrm{~N} 7 \mathrm{C} 11, \rho \mathrm{C} 11=\mathrm{O} 4$ & 886 & $\delta \mathrm{NO}_{2, \mathrm{vC} 15-\mathrm{N} 8}$ \\
\hline \multirow[t]{2}{*}{$908 \mathrm{~m}$} & 885 & $\delta \mathrm{NO}_{2}$ & 863 & $\gamma \mathrm{C} 16-\mathrm{H} 24$ \\
\hline & 862 & $\gamma \mathrm{C} 13-\mathrm{H} 23$ & 859 & $\gamma \mathrm{C} 13-\mathrm{H} 23$ \\
\hline $833 \mathrm{~m}$ & 842 & $\beta \mathrm{R}_{3}(\mathrm{~A} 1)$ & 850 & $\gamma \mathrm{C} 16-\mathrm{H} 24$ \\
\hline $826 \mathrm{~m}$ & 815 & $\delta \mathrm{NO}_{2,}, \rho \mathrm{C} 11=\mathrm{O} 4$ & 837 & $\gamma \mathrm{C} 19-\mathrm{H} 27$ \\
\hline $826 \mathrm{~m}$ & 802 & $\gamma \mathrm{C} 19-\mathrm{H} 27$ & 802 & $\delta \mathrm{NO}_{2}$ \\
\hline $768 \mathrm{sh}$ & 761 & $\gamma \mathrm{C} 11=\mathrm{O} 4, \gamma \mathrm{C} 10-\mathrm{C} 11$ & 759 & $\gamma \mathrm{C} 11=\mathrm{O} 4$ \\
\hline $751 \mathrm{~s}$ & 743 & $\gamma \mathrm{NO}_{2}$ & 742 & $\gamma \mathrm{NO}_{2}$ \\
\hline $740 \mathrm{sh}$ & 739 & $\beta \mathrm{R}_{3}(\mathrm{~A} 2)$ & 730 & $\beta \mathrm{R}_{3}(\mathrm{~A} 2)$ \\
\hline $711 w$ & 706 & $\tau \mathrm{R}_{1}(\mathrm{~A} 2), \gamma \mathrm{C} 9-\mathrm{N} 7$ & 717 & $\rho \mathrm{C} 11=\mathrm{O} 4, \mathrm{vC} 12-\mathrm{Cl} 1$ \\
\hline \multirow[t]{2}{*}{$689 w$} & 682 & $\gamma \mathrm{N} 7-\mathrm{H} 22, \gamma \mathrm{C} 14-\mathrm{O} 3$ & 698 & $\tau \mathrm{R}_{1}(\mathrm{~A} 2)$ \\
\hline & 681 & $\beta \mathrm{R}_{2}(\mathrm{~A} 2), \beta \mathrm{R}_{3}(\mathrm{~A} 1)$ & 690 & $\tau \mathrm{OH}$ \\
\hline \multirow[t]{2}{*}{$661 w$} & 661 & $\tau \mathrm{R}_{1}(\mathrm{~A} 1)$ & 671 & $\tau \mathrm{R}_{1}(\mathrm{~A} 1), \gamma \mathrm{C} 14-\mathrm{O} 3$ \\
\hline & 653 & $\beta \mathrm{R}_{2}(\mathrm{~A} 1)$ & 653 & $\beta \mathrm{R}_{2}(\mathrm{~A} 2)$ \\
\hline 639w & 637 & $\beta \mathrm{R}_{2}(\mathrm{~A} 2)$ & 649 & $\beta \mathrm{R}_{2}(\mathrm{~A} 1)$ \\
\hline $589 w$ & 560 & $\beta \mathrm{C} 14-\mathrm{O} 3$ & 602 & $\gamma \mathrm{N} 7-\mathrm{H} 22$ \\
\hline $557 \mathrm{w}$ & 549 & $\rho \mathrm{NO}_{2}$ & 557 & ${\rho \mathrm{NO}_{2}}_{2}$ \\
\hline $541 w$ & 542 & $\tau \mathrm{R}_{2}(\mathrm{~A} 1), \tau \mathrm{R}_{1}(\mathrm{~A} 2)$ & 535 & $\gamma \mathrm{C} 15-\mathrm{N} 8$ \\
\hline $532 w$ & 531 & $\tau \mathrm{R}_{2}(\mathrm{~A} 1), \tau \mathrm{R}_{3}(\mathrm{~A} 1)$ & 525 & $\tau \mathrm{R}_{2}(\mathrm{~A} 1)$ \\
\hline $504 w$ & & & 519 & $\beta \mathrm{C} 14-\mathrm{O} 3$ \\
\hline $467 w$ & & & 468 & $\beta C 9-N 7, v C 12-\mathrm{Cl1}$ \\
\hline $453 w$ & 454 & $\beta C 9-N 7$ & 447 & $\rho \mathrm{C} 11=\mathrm{O} 4$ \\
\hline $453 w$ & 446 & $\tau \mathrm{R}_{3}(\mathrm{~A} 2), \gamma \mathrm{C} 12-\mathrm{Cl} 1$ & & \\
\hline $435 w$ & 435 & $\tau \mathrm{R}_{3}(\mathrm{~A} 1)$ & 442 & $\gamma \mathrm{C} 12-\mathrm{Cl1}$ \\
\hline $417 w$ & 426 & $\beta \mathrm{C} 14-\mathrm{O} 3$ \&N7C11C10 & 428 & $\gamma \mathrm{C} 10-\mathrm{C} 11$ \\
\hline \multirow[t]{4}{*}{ 408w } & 397 & $v \mathrm{C} 10-\mathrm{C} 11, \beta \mathrm{R}_{2}(\mathrm{~A} 1)$ & 403 & $\beta \mathrm{R}_{3}(\mathrm{~A} 1)$ \\
\hline & 373 & $\mathrm{vC} 20-\mathrm{Cl} 2$ & 377 & $\beta \mathrm{C} 10-\mathrm{C} 11$ \\
\hline & 351 & vC12-Cl1 & 363 & $v \mathrm{C} 20-\mathrm{Cl} 2$ \\
\hline & 342 & $\tau \mathrm{R}_{3}(\mathrm{~A} 1), \gamma \mathrm{C} 20-\mathrm{Cl} 2$ & 344 & $\beta \mathrm{C} 12-\mathrm{Cl} 1, \rho \mathrm{NO}_{2}$ \\
\hline
\end{tabular}




\begin{tabular}{|c|c|c|c|c|}
\hline \multirow{3}{*}{$\begin{array}{c}\text { Experimental }^{\mathrm{d}} \\
\text { ATR }^{\mathrm{c}} \\
\end{array}$} & \multicolumn{4}{|c|}{ B3LYP/6-31G* Method $^{a}$} \\
\hline & \multicolumn{2}{|r|}{ C1 } & \multicolumn{2}{|r|}{$\mathrm{C2}$} \\
\hline & SQM$^{\mathbf{b}}$ & Assignments & $\mathbf{S Q M}^{\mathbf{b}}$ & Assignments \\
\hline & 338 & $\beta \mathrm{C} 10-\mathrm{C} 11$ & 335 & $\tau \mathrm{R}_{3}(\mathrm{~A} 1), \gamma \mathrm{C} 20-\mathrm{Cl} 2$ \\
\hline & 326 & $\gamma \mathrm{C} 20-\mathrm{Cl} 2$ & 321 & $\gamma \mathrm{C} 20-\mathrm{Cl} 2$ \\
\hline & 269 & $\tau \mathrm{OH}$ & 269 & $\beta \mathrm{C} 20-\mathrm{Cl} 2, \delta \mathrm{N} 7 \mathrm{C} 11 \mathrm{C} 10$ \\
\hline & 265 & $\beta \mathrm{C} 20-\mathrm{Cl} 2$ & & \\
\hline & 200 & $\beta \mathrm{C} 12-\mathrm{Cl1}$ & 208 & $\beta \mathrm{C} 15-\mathrm{N} 8$ \\
\hline & & & 178 & $\beta C 12-\mathrm{Cl1}$ \\
\hline & 174 & $\tau \mathrm{R}_{2}(\mathrm{~A} 2)$ & 173 & $\tau \mathrm{R}_{2}(\mathrm{~A} 2) \tau \mathrm{R}_{3}(\mathrm{~A} 2)$ \\
\hline & 165 & $\gamma \mathrm{C} 15-\mathrm{N} 8$ & & \\
\hline & 163 & $\beta \mathrm{C} 15-\mathrm{N} 8$ & 164 & $\gamma \mathrm{C} 15-\mathrm{N} 8, \tau \mathrm{N} 7-\mathrm{C} 11$ \\
\hline & 148 & $\beta \mathrm{C} 20-\mathrm{Cl} 2, \beta \mathrm{C} 10-\mathrm{C} 11$ & & \\
\hline & & & 132 & $\tau \mathrm{R}_{2}(\mathrm{~A} 1), \tau \mathrm{OH}$ \\
\hline & 127 & $\tau \mathrm{R}_{2}(\mathrm{~A} 2), \tau \mathrm{R}_{3}(\mathrm{~A} 1)$ & 130 & $\tau \mathrm{R}_{3}(\mathrm{~A} 1)$ \\
\hline & 107 & $\tau \mathrm{R}_{2}(\mathrm{~A} 1), \tau \mathrm{R}_{3}(\mathrm{~A} 1)$ & 116 & $\tau \mathrm{R}_{2}(\mathrm{~A} 2)$ \\
\hline & 64 & $\delta \mathrm{N} 7 \mathrm{C} 11 \mathrm{C} 10$ & 67 & $\tau \mathrm{C} 11-\mathrm{C} 10, \tau \mathrm{N} 7-\mathrm{C} 9$ \\
\hline & 59 & $\tau \mathrm{wNO}{ }_{2}$ & 53 & $\tau \mathrm{wNO}_{2}$ \\
\hline & 48 & $\tau \mathrm{N} 7-\mathrm{C} 9$ & 48 & $\tau \mathrm{C} 11-\mathrm{C} 10$ \\
\hline & 23 & $\tau \mathrm{N} 7-\mathrm{C} 11$ & 26 & $\tau \mathrm{N} 7-\mathrm{C} 11$ \\
\hline & 11 & $\tau \mathrm{C} 11-\mathrm{C} 10$ & 13 & $\tau \mathrm{N} 7-\mathrm{C} 9$ \\
\hline
\end{tabular}

Abbreviations: $v$, stretching; $\delta$, deformation in the plane; $\gamma$, deformation out of the plane; wag, wagging; $\tau$, torsion; $\beta_{\mathrm{R}}$, deformation ring $\tau_{\mathrm{R}}$, torsion ring; $\rho$, rocking; $\tau \mathrm{w}$, twisting; $\delta$, deformation; a, antisymmetric; s, symmetric; $\left(\mathrm{A}_{1}\right)$, Ring R1; $\left(\mathrm{A}_{2}\right)$, Ring R2. ${ }^{\mathrm{a}}$ This work, ${ }^{\mathrm{b}}$ From scaled quantum mechanics force field; ${ }^{\mathrm{c}}$ From Ref [62].

2000-1000 $\mathrm{cm}^{-1}$ Region. The $\mathrm{C}=\mathrm{O}$ stretching mode is predicted in $\mathrm{C} 1$ at $1707 \mathrm{~cm}^{-1}$ while in $\mathrm{C} 2$ at $1672 \mathrm{~cm}^{-1}$. This difference in $\mathrm{C} 2$ is related to the two $\mathrm{H}$ bonds formed by the $\mathrm{C}=\mathrm{O}$ group, as evidenced by the AIM study. Note that the intensities of these bands in both $\mathrm{C} 1$ and $\mathrm{C} 2$ conformers are different from that intense expected for these groups because the experimental ATR spectrum was recorded in mull of nujol, whose intense band at $751 \mathrm{~cm}^{-1}$ overlaps with the band corresponding to $\mathrm{NO}_{2}$ groups in this region diminishing the intensities ratio between these bands. The anti-symmetrical $\left(v_{\mathrm{a}}\right)$ and symmetrical $\left(v_{\mathrm{s}}\right) \mathrm{NO}_{2}$ stretching modes in $\mathrm{C} 1$ are assigned to the strong bands at 1607 and $1331 \mathrm{~cm}^{-1}$ while for $\mathrm{C} 2$, the bands at 1657 and $1331 \mathrm{~cm}^{-1}$ can be assigned to those two stretching modes. The $\mathrm{C}=\mathrm{C}$ stretching modes of both rings with double and partial bond characters of two conformers can be assigned to the IR bands between 1632 and $1331 \mathrm{~cm}^{-1}$ while the bending or in-plane deformation of $\mathrm{CH}$ groups $(\beta \mathrm{C}-\mathrm{H})$ can be attributed to the bands between 1470 and $116 \mathrm{~cm}^{-1}$. The $\mathrm{OH}$ deformation modes are predicted for $\mathrm{C} 1$ and $\mathrm{C} 2$ in different regions. Thus these modes can be assigned to the bands at 116 and $1331 \mathrm{~cm}^{-1}$, respectively. In $\mathrm{C} 1$, that mode is observed at lower wavenumbers due to the $\mathrm{H}$ bond formed between the N7-H22 and O3-H29 groups, as revealed by AIM analysis. The N-C stretching modes can also be assigned in this region because the SQM calculations predicted these modes in these regions [24-29,31,32].

$1000-10 \mathrm{~cm}^{-1}$ Region. In this region are expected the $\mathrm{NO}_{2}$ deformation $(\delta)$, rocking $(\rho)$ and out-of-plane deformation modes $(\gamma)$ for $\mathrm{C} 1$ and C2. The SQM calculations predicted in approximately the same regions for both forms. Thus, the IR bands at 908,826 , and $751 \mathrm{~cm}^{-1}$ can be assigned to those vibration modes, respectively. The three deformations and torsion ring modes of chloro-4-nitrophenyl, and hydroxybenzamide rings are assigned in those regions predicted by calculations, as detailed in Table 7 [23-32,50-56]. The remaining vibration modes are assigned as predicted by the SQM calculations and, in accordance with assignments reported for species with similar rings [23-32,50-56]. 


\subsection{Force Fields.}

The harmonic force constants were calculated for both forms of niclosamide because these parameters can predict the forces of different bonds and, hence, the formations of $\mathrm{H}$ bonds. Thus, the force constants for $\mathrm{C} 1$ and $\mathrm{C} 2$ were obtained from corresponding force fields by using the SQMFF methodology and the Molvib program [34-36]. Therefore, the harmonic force constants calculated for both forms of niclosamide in the gas phase with functional hybrid B3LYP and the 6-31G* basis set are given in Table 8 compared with those published for 2-(4 nitrophenyl)-4H-3,1-benzoxacin-4-one) at the same level of theory [65]. Some important differences can be observed when the values for $\mathrm{C} 1$ and $\mathrm{C} 2$ are compared. Hence, the differences in the values of $f(v N-H), f(v O-H), f(\nu C=O)$, and $f(\delta O-H)$ force constants are related to the groups involved in the $\mathrm{H}$ bonds formation.

Table 8. Scaled internal force constants for conformers $\mathrm{C} 1$ and $\mathrm{C} 2$ of antiviral niclosamide in gas phase by using the hybrid B3LYP level of theory.

\begin{tabular}{c|c|c|c}
\hline \multirow{2}{*}{ Force constant } & \multicolumn{2}{|c|}{ Niclosamide $^{\mathrm{a}}$} & \multirow{2}{*}{$\begin{array}{c}\text { 2-(4 nitrophenyl)-4H- } \\
\text { 3,1-benzoxacin-4-one) }\end{array}$} \\
\cline { 2 - 3 } & $\mathrm{C} 1$ & $\mathrm{C} 2$ & \\
\hline$f(v N-H)$ & 6.37 & 6.65 & \\
\hline$f(v O-H)$ & 7.27 & 5.77 & \\
\hline$f(v C=O)$ & 11.29 & 10.31 & 12.758 \\
\hline$f\left(v N \mathrm{O}_{2}\right)$ & 9.64 & 9.69 & 9.735 \\
\hline$f(v N-C)_{N H}$ & 6.02 & 5.99 & 7.590 \\
\hline$f(v C-N)_{N O 2}$ & 4.15 & 4.12 & \\
\hline$f(v C-H)_{R 1}$ & 5.38 & 5.39 & \\
\hline$f(v C-H)_{R 2}$ & 5.22 & 5.23 & 5.266 \\
\hline$f(v C-C l)$ & 3.28 & 3.28 & $3.304^{\#}$ \\
\hline$f\left(\delta N O_{2}\right)$ & 1.61 & 1.60 & \\
\hline$f(\delta O-H)$ & 0.72 & 1.04 & \\
\hline
\end{tabular}

Units are mdyn $\AA^{-1}$ for stretching and mdyn $\AA \operatorname{rad}^{-2}$ for angle deformations, ${ }^{\text {a This work, }}{ }^{\text {b }}$ From Ref [65], ${ }^{\#}$ For 2(4-chlorophenyl)-4H-3,1-benzoxazin-4-one

Thus, in $\mathrm{C} 1$, those force constants are slightly higher than the observed in $\mathrm{C} 2$ while a higher difference in $\mathrm{C} 2$ it is evidenced in the $f(\delta O-H)$ force constant, as compared with $\mathrm{C} 1$. This diminishing in the value can be due to that in $\mathrm{C} 1$; the bond C14-O3-H29 angle is not involved in the $\mathrm{H}$ bond formation. In contrast, in $\mathrm{C} 2$ with the formation of $\mathrm{C} 11-\mathrm{O} 4 \cdots \mathrm{H} 23$ bond that angle participle in this new $\mathrm{H}$ bond. When the values are compared with the predicted for 2-(4 nitrophenyl)-4H-3,1-benzoxacin-4-one) higher values in the force constants are observed for that derivative. Such differences can be easily attributed to the presence of two deactivating groups in niclosamide. In comparison, in that derivative in the nitrophenyl ring, there is only the $\mathrm{NO}_{2}$ group different from niclosamide that presents two deactivating groups $\left(\mathrm{NO}_{2}\right.$ and $\mathrm{Cl}$ group).

\subsection{Molecular docking studies.}

According to $\mathrm{Wu}$ et al. [66], the niclosamide molecule has been demonstrated to have an anti-SARS-CoV activity. For that, in the present paper, we tested with COVID-19; i.e., we performed the molecular docking characteristics of NCL $\mathrm{C}_{1}$ (in the gas phase) and $\mathrm{C}_{2}$ (in gas and water solution) against COVID-19 protein (code: 6LU7) [67]. 


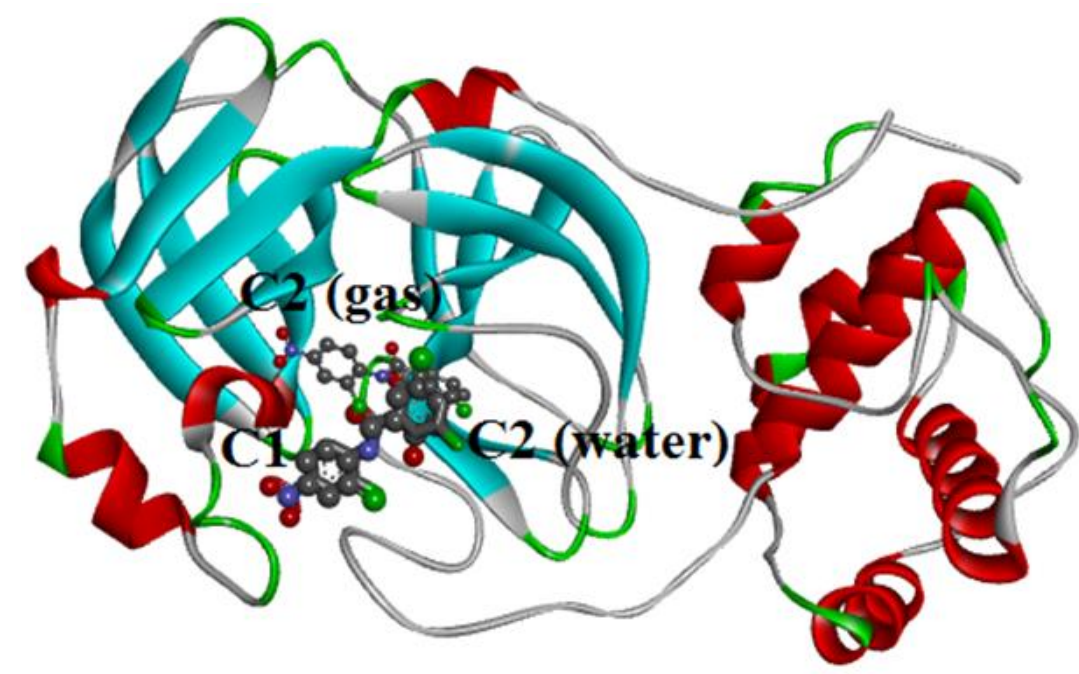

Figure 6. The best-docked poses of the Niclosamide $\mathrm{C}_{2}$ (in the gas phase and water) and its conformer $\mathrm{C} 1$ (in the gas phase) in the COVID-19 protein.


(b)
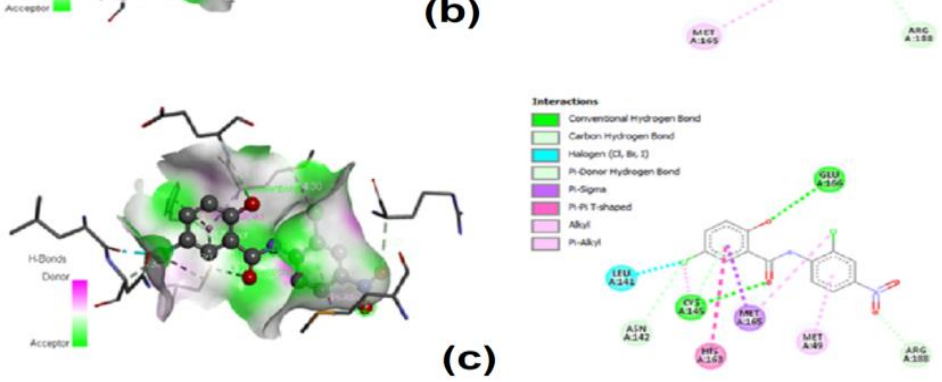

Figure 7. $\mathrm{H}$-bonding interactions between ligands and protein and their $2 \mathrm{D}$ interactions. $\left(\mathrm{a} / \mathrm{C}_{2}\right.$ (in water)/COVID-19; $\mathrm{b} / \mathrm{C}_{2}$ (in gas)/COVID-19 and c/ $\mathrm{C}_{1}$ (in gas)/COVID-19.

The objective of these calculations is to provide the binding mode of these ligands with a Coronavirus containing a 3D structure. The inhibition of this protein could be an attractive target for the treatment of coronavirus. So, three complexes comprising ligands-protein were selected. In Fig. 6, we present the best-docked poses of the different ligands (having the lowest energy from the ten total poses) in the COVID-19 protein obtained by using iGEMDOCK software with the following setting: population size is 800 , number 10 of generations is 80 and number of solutions is 10 . The energetic results are given in Table 9, distributed into three types of non-covalent interactions: van der Waals, hydrogen-bond and electronic interactions.

Results predicted a good total energy score of the different ligands with the selected target. Docking calculations led to the following values: the total energies scores are equal to 104.658, -97.507 and $-95.362 \mathrm{Kcal} / \mathrm{mol}$ for $\mathrm{C}_{2}$ (in water), $\mathrm{C}_{2}$ (in the gas phase) and $\mathrm{C}_{1}$ (in gas), respectively. It can be seen that the niclosamide $\mathrm{C}_{2}$ in aqueous solution has the strongest binding ligand with an energy score equal to $-104.658 \mathrm{kcal} / \mathrm{mol}$. Also, it possesses the strongest 
van der Waals $(-87.899 \mathrm{kcal} / \mathrm{mol})$ and electronic interactions $(0.315 \mathrm{kcal} / \mathrm{mol})$. This indicates that the anchored inhibitors interacted strongly with $\mathrm{C}_{2}$ in water. This finding confirms the fact that the title compound $\left(\mathrm{C}_{2}\right)$ in water is a good inhibitor against the COVID-19 better than in the gas phase. Calculations show clearly that the predominant interaction is of VDW type. For the COVID-19/C2 (in water), S-HIS-41, M-MET-49, M-HIS-164, M-MET-165, M-ARG-188, and S-GLN-189 residues formed VDW interactions; while S-HIS-41, S-TYR-54 and S-CYS145 form H-bond interactions (as illustrated in fig. 7). In the gas phase, we notice that the total energies score of the $\mathrm{C}_{2}(-71.052 \mathrm{kcal} / \mathrm{mol})$ is greater than those calculated for $\mathrm{C}_{1}(-80.049$ $\mathrm{kcal} / \mathrm{mol}$ ). Finally and according to the docking results, we can conclude that the niclosamide molecule is a potent inhibitor against coronavirus, since it penetrates well into the active site of the COVID-19.

Table 9. Molecular docking energies and their distributions as non-covalent interactions.

\begin{tabular}{|c|c|c|c|c|c|c|c|}
\hline $\begin{array}{l}\text { Target } \\
\text { protein }\end{array}$ & Ligand & $\begin{array}{c}\text { Total } \\
\text { energy }\end{array}$ & VDW & H-bond & Electronic & $\begin{array}{l}\text { Binding } \\
\text { residue }\end{array}$ & Bond name \\
\hline \multirow{24}{*}{ COVID-19 } & \multirow{9}{*}{$\begin{array}{l}\text { Niclosamide } \\
\text { C2 (in } \\
\text { water) }\end{array}$} & \multirow{9}{*}{-104.658} & \multirow{9}{*}{-87.899} & \multirow{9}{*}{-17.074} & \multirow{9}{*}{0.315} & S-HIS-41 & H-bond \\
\hline & & & & & & S-TYR-54 & H-bond \\
\hline & & & & & & S-CYS-145 & H-bond \\
\hline & & & & & & S-HIS-41 & VDW \\
\hline & & & & & & M-MET-49 & VDW \\
\hline & & & & & & M-HIS-164 & VDW \\
\hline & & & & & & M-MET- & VDW \\
\hline & & & & & & M-ARG- & VDW \\
\hline & & & & & & S-GLN-189 & VDW \\
\hline & \multirow{7}{*}{$\begin{array}{l}\text { Niclosamide } \\
\text { C2 (in gas) }\end{array}$} & \multirow{7}{*}{-97.507} & \multirow{7}{*}{-71.052} & \multirow{7}{*}{-26.455} & \multirow{7}{*}{0} & M-THR-26 & H-bond \\
\hline & & & & & & M-GLY- & H-bond \\
\hline & & & & & & M-SER-144 & H-bond \\
\hline & & & & & & $\begin{array}{c}\text { S-SER-144 } \\
\text { M-CYS-145 }\end{array}$ & H-bond \\
\hline & & & & & & S-CYS-145 & H-bond \\
\hline & & & & & & S-HIS-163 & H-bond \\
\hline & & & & & & M-LEU-141 & H-bond \\
\hline & \multirow{8}{*}{$\begin{array}{l}\text { Niclosamide } \\
\text { C1 (in gas) }\end{array}$} & \multirow{8}{*}{-95.362} & \multirow{8}{*}{-80.049} & \multirow{8}{*}{-15.591} & \multirow{8}{*}{0.279} & S-CYS-44 & H-bond \\
\hline & & & & & & S-TYR-54 & H-bond \\
\hline & & & & & & S-HIS-41 & VDW \\
\hline & & & & & & S-MET-49 & VDW \\
\hline & & & & & & S-TYR-54 & VDW \\
\hline & & & & & & M-HIS-164 & VDW \\
\hline & & & & & & M-ARG- & VDW \\
\hline & & & & & & S-GLN-189 & VDW \\
\hline
\end{tabular}

Note that the total energy represents the sum of these three interactions. Fig. 7 ( $a, b$ and $\mathrm{c}$,) shows the hydrogen bonding interactions between ligands/protein and their 2D interactions, visualized in the Discovery Studio program.

\section{Conclusions}

Here, the effect of medium on properties and reactivities of potential antiviral to the treatment of COVID-19, niclosamide (NCL) have been studied combining DFT calculations with molecular docking. The structures of the two most stable conformers $\mathrm{C} 1$ and $\mathrm{C} 2$ were theoretically determined in the gas phase and water, ethanol, and chloroform solvents by using 
B3LYP/6-31G* calculations. The structural, electronic, topological, and vibrational properties of niclosamide were reported in the four studied media. The properties in the different solvents were studied by using the IEFPCM and universal solvation methods. The calculations in the different solutions have revealed solvation energy values for $\mathrm{C} 1$ and $\mathrm{C} 2$ in aqueous solution $\left(\Delta \mathrm{G}_{\mathrm{C}}=-78.43\right.$ and $-64.53 \mathrm{~kJ} / \mathrm{mol}$, respectively) comparable with that observed for the antiviral agent zalcitabine $(-78.92 \mathrm{~kJ} / \mathrm{mol})$. Probably, the high stability of $\mathrm{C} 1$, predicted by NBO studies, explains the experimental existence of $\mathrm{C} 1$ structure in the solid phase. Comparisons of frontier orbitals with eleven antiviral agents have evidenced the slightly high reactivity of $\mathrm{C} 2$ than brincidofovir, an antiviral agent used in the treatment of Ebola disease. Despite less negative solvation energy values of $\mathrm{C} 1$ and $\mathrm{C} 2$ in aqueous solution, as compared with eleven antiviral agents, the presence of deactivating groups $\left(\mathrm{NO}_{2}\right.$ and $\left.\mathrm{Cl}\right)$ in the chloro-4-nitrophenyl and hydroxybenzamide rings could explain the higher reactivities observed for the two forms of NCL in different media. Here, the harmonic force fields and force constants for both forms are reported together with the assignments of 80 vibration modes expected for the two conformers.

Molecular docking results were discussed based on the type of interaction between the ligands and protein. The studies of molecular docking have shown that the niclosamide could bind to the new 2019-nCoV protein with high affinity. The three complexes showed important total energy, which makes them an important candidate to study. Finally, we hope that our contribution can help to develop a rigorous solution for this worldwide concern.

\section{Funding}

This work was supported by grants from CIUNT Project No 26/D608 (Consejo de Investigaciones, Universidad Nacional de Tucumán, Argentina).

\section{Acknowledgments}

The authors would like to thank Prof. Tom Sundius for his permission to use MOLVIB.

\section{Conflicts of Interest}

The authors declare no conflict of interest.

\section{Supporting Information Available}

Tables S1-S6 and Figures S1-S6.

\section{References}

1. World Health Organization. Novel Coronavirus-Japan (ex-China). Available online: https://www.who.int/csr/don/16-january-2020-novel-coronavirus-japan-ex-china/en/ (accessed on 19 January 2020).

2. Ji, W.; Wang, W.; Zhao, X.; Zai, J.; Li, X. Homologous recombination within the spike glycoprotein of the newly identified coronavirus may boost cross-species transmission from snake to human. Journal of Medical Virology 2020, 92, https://doi.org/10.1002/jmv.25682.

3. Zhu, N.; Zhang, D.; Wang, W.; Li, X.; Yang, B.; Song, J.; Zhao, X.; Huang, B.; Shi, W.; Lu, R.; Niu, P.; Zhan, F.; Ma, X.; Wang, D.; Xu, W.; Wu, G.; Gao, G.F.; Tan, W. A Novel Coronavirus from Patients with Pneumonia in China, 2019. New England Journal of Medicine 2020, 382, 727-733, https://doi.org/10.1056/NEJMoa2001017.

4. Zhou, P.; Yang, X.L.; Wang, X.G.; Hu, B.; Zhang, L.; Zhang, W.; Si, H.R.; Zhu, Y.; Li, B.; Huang, C.L.; Chen, H.D.; Chen, J.; Luo, Y.; Guo, H.; Jiang, R.D.; Liu, M.Q.; Chen, Y.; Shen, X.R.; Xiao, G. Discovery of a novel coronavirus associated with the recent pneumonia outbreak in humans and its potential bat origin. 2020; https://doi.org/10.1101/2020.01.22.914952.

5. Available on line: https://www.wwpdb.org/pdb?id=pdb_00006lu7

https://biointerfaceresearch.com/ 
6. $\quad$ ang, H.; Xie, W.; Xue, X.; Yang, K.; Ma, J.; Liang, W.; Zhao, Q.; Zhou, Z.; Pei, D.; Ziebuhr, J.; Hilgenfeld, R.; Yuen, K.Y.; Wong, L.; Gao, G.; Chen, S.; Chen, Z.; Ma, D.; Bartlam, M.; Rao, Z. Design of widespectrum inhibitors targeting coronavirus main proteases. PLoS Biol 2005, 3, https://doi.org/10.1371/journal.pbio.0030324.

7. Teengam, P.; Siangproh, W.; Tuantranont, A.; Vilaivan, T.; Chailapakul, O.; Henry, C.S. Multiplex PaperBased Colorimetric DNA Sensor Using Pyrrolidinyl Peptide Nucleic Acid-Induced AgNPs Aggregation for Detecting MERS-CoV, MTB, and HPV Oligonucleotides. Analytical Chemistry 2017, 89, 5428-5435, https://doi.org/10.1021/acs.analchem.7b00255.

8. Huang, C.; Qi, J.; Lu, G.; Wang, Q.; Yuan, Y.; Wu, Y.; Zhang, Y.; Yan, J.; Gao, G.F. Putative Receptor Binding Domain of Bat-Derived Coronavirus HKU9 Spike Protein: Evolution of Betacoronavirus Receptor Binding Motifs. Biochemistry 2016, 55, 5977-5988, https://doi.org/10.1021/acs.biochem.6b00790.

9. Liu, C.; Zhou, Q.; Li, Y.; Garner, L.V.; Watkins, S.P.; Carter, L.J.; Smoot, J.; Gregg, A.C.; Daniels, A.D.; Jervey, S.; Albaiu, D. Research and Development on Therapeutic Agents and Vaccines for COVID-19 and Related Human Coronavirus Diseases. ACS Central Science 2020, 6, 315-331, https://dx.doi.org/10.1021/acscentsci.0c00272.

10. Baig, A.M.; Khaleeq, A.; Ali, U.; Syeda, H. Evidence of the COVID-19 Virus Targeting the CNS: Tissue Distribution, Host-Virus Interaction, and Proposed Neurotropic Mechanisms. ACS Chemical Neuroscience 2020, 11, 995-998, https://dx.doi.org/10.1021/acschemneuro.0c00122.

11. Yoon, J.S.; Kim, G.; Jarhad, D.B.; Kim, H.R.; Shin, Y.S.; Qu, S.; Sahu, P.K.; Kim, H.O.; Lee, H.W.; Wang, S.B.; Kong, Y.J.; Chang, T.S.; Ogando, N.S.; Kovacikova, K.; Snijder, E.J.; Posthuma, C.C.; van Hemert, M.J.; Jeong, L.S. Design, Synthesis, and Anti-RNA Virus Activity of 6'-Fluorinated-Aristeromycin Analogues. Journal of Medicinal Chemistry 2019, 62, 6346-6362, https://doi.org/10.1021/acs.jmedchem.9b00781.

12. Xu, J.; Shi, P.Y.; Li, H.; Zhou, J. Broad Spectrum Antiviral Agent Niclosamide and Its Therapeutic Potential. ACS Infectious Diseases 2020, 6, 909-915, https://dx.doi.org/10.1021/acsinfecdis.0c00052.

13. Xiang, D.F.; Bigley, A.N.; Desormeaux, E.; Narindoshvili, T.; Raushel, F.M. Enzyme-Catalyzed Kinetic Resolution of Chiral Precursors to Antiviral Prodrugs. Biochemistry 2019, 58, 3204-3211, https://doi.org/10.1021/acs.biochem.9b00530.

14. Liu, S.L.; Wang, Z.G.; Xie, H.Y.; Liu, A.A.; Lamb, D.C.; Pang, D.W. Single-Virus Tracking: From Imaging Methodologies to Virological Applications. Chem. Rev. 2020, 120, 1936-1979, https://doi.org/10.1021/acs.chemrev.9b00692.

15. Wang, C.; Zhao, L.; Xia, S.; Zhang, T.; Cao, R.; Liang, G.; Li, Y.; Meng, G.; Wang, W.; Shi, W.; Zhong, W.; Jiang, S.; Liu, K. De Novo Design of $\alpha$-Helical Lipopeptides Targeting Viral Fusion Proteins: A Promising Strategy for Relatively Broad-Spectrum Antiviral Drug Discovery. J Med Chem 2018, 61, 87348745, https://doi.org/10.1021/acs.jmedchem.8b00890.

16. Zhang, L.; Lin, D.; Kusov, Y.; Nian, Y.; Ma, Q.; Wang, J.; von Brunn, A.; Leyssen, P.; Lanko, K.; Neyts, J.; de Wilde, A.; Snijder, E.J.; Liu, H.; Hilgenfeld, R. $\alpha$-Ketoamides as Broad-Spectrum Inhibitors of Coronavirus and Enterovirus Replication: Structure-Based Design, Synthesis, and Activity Assessment. Journal of Medicinal Chemistry 2020, 63, 4562-4578, https://dx.doi.org/10.1021/acs.jmedchem.9b01828.

17. Lin, S.M.; Lin, S.C.; Hsu, J.N.; Chang, C.K.; Chien, C.M.; Wang, Y.S.; Wu, H.Y.; Jeng, U.S.; Kehn-Hall, K.; Hou, M.H. Structure-Based Stabilization of Non-native Protein-Protein Interactions of Coronavirus Nucleocapsid Proteins in Antiviral Drug Design. Journal of Medicinal Chemistry 2020, 63, 3131-3141, https://dx.doi.org/10.1021/acs.jmedchem.9b01913.

18. Łoczechin, A.; Séron, K.; Barras, A.; Giovanelli, E.; Belouzard, S.; Chen, Y.-T.; Metzler-Nolte, N.; Boukherroub, R.; Dubuisson, J.; Szunerits, S. Functional Carbon Quantum Dots as Medical Countermeasures to Human Coronavirus. ACS Applied Materials \& Interfaces 2019, 11, 42964-42974, https://doi.org/10.1021/acsami.9b15032.

19. Wang, Q.; Zhang, L.; Kuwahara, K.; Li, L.; Liu, Z.; Li, T.; Zhu, H.; Liu, J.; Xu, Y.; Xie, J.; Morioka, H.; Sakaguchi, N.; Qin, C.; Liu, G. Immunodominant SARS Coronavirus Epitopes in Humans Elicited both Enhancing and Neutralizing Effects on Infection in Non-human Primates. ACS Infect Dis 2016, 2, 361-376, https://doi.org/10.1021/acsinfecdis.6b00006.

20. Lee, H.; Lei, H.; Santarsiero, B.D.; Gatuz, J.L.; Cao, S.; Rice, A.J.; Patel, K.; Szypulinski, M.Z.; Ojeda, I.; Ghosh, A.K.; Johnson, M.E. Inhibitor Recognition Specificity of MERS-CoV Papain-like Protease May Differ from That of SARS-CoV. ACS Chem. Biol. 2015, 10, 1456-1465, https://doi.org/10.1021/cb500917m.

21. De Clercq, E. Antiviral drugs: current state of the art. J Clin Virol. 2001, 22, 73-89, https://doi.org/10.1016/s1386-6532(01)00167-6.

22. De Clercq, E. Antiviral drugs in current clinical use. Journal of Clinical Virology 2004, 30, 115-133, https://doi.org/10.1016/j.jcv.2004.02.009.

23. Márquez, M.B.; Brandán, S.A. A structural and vibrational investigation on the antiviral deoxyribonucleoside thymidine agent in gas and aqueous solution phases. International Journal of Quantum Chemistry 2014, 114, 209-221, https://doi.org/10.1002/qua.24545. 
24. Romani, D.; Márquez, M.J.; Márquez, M.B.; Brandán, S.A. Structural, topological and vibrational properties of an isothiazole derivatives series with antiviral activities. J. Mol. Struct. 2015, 1100, 279-289, http://dx.doi.org/10.1016/j.molstruc.2015.07.038.

25. Checa, M.A.; Rudyk, R.A.; Chamorro, E.E.; Brandán, S.A. Chapter 1-Structural and Vibrational Properties of a reverse Inhibitor against the HIV Virus, Dideoxynucleoside Zalcitabine in Gas and Aqueous Solution Phases. In: Descriptors, Structural and spectroscopic Properties of Heterocyclic derivatives of importance for the health and the enviromental. Brandán, S.A. Edit. Edited Collection, Nova Science Publishers, Inc. 2015; pp. 1-26.

26. Brandán, S.A. Structural, topological, electronic and vibrational properties of the antiviral trifluridine agent. their comparison with thymidine. Paripex A Indian Journal of Res. 2017, 6, 346-360.

27. Romani, D.; Brandán, S.A. Spectroscopic and Structural Study of the Antiviral Idoxuridine Agent by Using DFT and SCRF Calculations. International Journal of Science And Research Methodology 2017, 8, 66-86.

28. Romani, D.; Brandán, S.A. Investigating the Structural and Vibrational Properties of the Nucleoside Reverse Transcriptase Inhibitor Emtricitabine. International Journal of Science And Research Methodology 2017, 8, 236-277.

29. Iramain, M.A.; Ledesma, A.E.; Romani, D.; Brandán, S.A. Structural, electronic, topological and vibrational properties of isomers of thymidine. A study combining spectroscopic data with DFT calculations. International Journal of Science And Research Methodology 2017, 8, 197-238.

30. Iramain, M.A.; Brandán, S.A. Structural and vibrational study on the acid, hexa-hydrated and anhydrous trisodic salts of antiviral drug Foscarnet. Drug Designing \& Intellectual Properties International Journal 2018, 1, 1-17, http://dx.doi.org/10.32474/DDIPIJ.2018.01.000114.

31. Ladetto, M.F.; Márquez, M.J.; Romani, D.; Brandán, S.A. Structural and vibrational properties of the antiviral ribavirin drug in gas and aqueous environmental. A complete assignment of their vibrational spectra. Journal of Advances In Chemistry 2019, 16, 6325-6353.

32. Romani, D.; Brandán, S.A. Effect of the side chain on the properties from cidofovir to brincidofovir, an experimental antiviral drug against to Ebola virus disease. Arabian Journal of Chemistry 2019, 12, 29592972, http://dx.doi.org/10.1016/j.arabjc.2015.06.030.

33. Sanphui, P.; Kumar, S.S.; Nangia, A. Pharmaceutical Cocrystals of Niclosamide. Cryst. Growth Des. 2012, 12, 4588-4599, https://doi.org/10.1021/cg300784v.

34. Pulay, P.; Fogarasi, G.; Pongor, G.; Boggs, J.E.; Vargha, A. Combination of theoretical ab initio and experimental information to obtain reliable harmonic force constants. Scaled quantum mechanical (QM) force fields for glyoxal, acrolein, butadiene, formaldehyde, and ethylene. Journal of the American Chemical Society 1983, 105, 7037-7047, https://doi.org/10.1021/ja00362a005.

35. Rauhut, G.; Pulay, P. Transferable Scaling Factors for Density Functional Derived Vibrational Force Fields. The Journal of Physical Chemistry 1995, 99, 3093-3100, https://doi.org/10.1021/j100010a019.

36. Sundius, T. Scaling of ab initio force fields by MOLVIB. Vibrational Spectroscopy 2002, 29, 89-95, https://doi.org/10.1016/S0924-2031(01)00189-8.

37. Sanphui, P.; Kumar, S.S.; Nangia, A. CCDC 892335: Experimental Crystal Structure Determination. 2013, https://doi.org/10.5517/ccyyk0f.

38. Nielsen, A.B.; Holder, A.J. Gauss View 3.0, User's Reference, GAUSSIAN Inc.; Pittsburgh, PA, 20002003.

39. Gaussian 09, Revision A.02, Frisch, M.J.; Trucks, G.W.; Schlegel, H.B.; Scuseria, G.E.; Robb, M.A.; Cheeseman, J.R.; Scalmani, G.; Barone, V.; Mennucci, B.; Petersson, G.A.; Nakatsuji, H.; Caricato, M.; Li, X.; Hratchian, H.P.; Izmaylov, A.F.; Bloino, J.; Zheng, G.; Sonnenberg, J.L.; Hada, M.; Ehara, M.; Toyota, K.; Fukuda, R.; Hasegawa, J.; Ishida, M.; Nakajima, T.; Honda, Y.; Kitao, O.; Nakai, H.; Vreven, T.; Montgomery, J.A.; Peralta, J.E.; Ogliaro, F.; Bearpark, M.; Heyd, J.J.; Brothers, E.; Kudin, K.N.; Staroverov, V.N.; Kobayashi, R.; Normand, J.; Raghavachari, K.; Rendell, A.; Burant, J.C.; Iyengar, S.S.; Tomasi, J.; Cossi, M.; Rega, N.; Millam, J.M.; Klene, M.; Knox, J.E.; Cross, J.B.; Bakken, V.; Adamo, C.; Jaramillo, J.; Gomperts, R.; Stratmann, R.E.; Yazyev, O.; Austin, A.J.; Cammi, R.; Pomelli, C.; Ochterski, J.W.; Martin, R.L.; Morokuma, K.; Zakrzewski, V.G.; Voth, G.A.; Salvador, P.; Dannenberg, J.J.; Dapprich, S.; Daniels, A.D.; Farkas, O.; Foresman, J.B.; Ortiz, J.; Cioslowski, J.; Fox, D.J. Gaussian, Inc.; Wallingford CT, 2009.

40. Becke, A.D. Density-functional exchange-energy approximation with correct asymptotic behavior. Phys. Rev. 1988, A38, 3098-3100, https://doi.org/10.1103/physreva.38.3098.

41. Lee, C.; Yang, W.; Parr, R.G. Development of the Colle-Salvetti correlation-energy formula into a functional of the electron density. Phys. Rev. 1988, B37, 785-789, https://doi.org/10.1103/PhysRevB.37.785.

42. Miertuš, S.; Scrocco, E.; Tomasi, J. Electrostatic interaction of a solute with a continuum. A direct utilizaion of AB initio molecular potentials for the prevision of solvent effects. Chemical Physics 1981, 55, 117-129, https://doi.org/10.1016/0301-0104(81)85090-2.

43. Tomasi, J.; Persico, J. Molecular Interactions in Solution: An Overview of Methods Based on Continous Distributions of the Solvent. Chem. Rev. 1994, 94, 2027-2094, https://doi.org/10.1021/cr00031a013. 
44. Marenich, A.V.; Cramer, C.J.; Truhlar, D.G. Universal solvation model based on solute electron density and a continuum model of the solvent defined by the bulk dielectric constant and atomic surface tensions. $J$. Phys. Chem. 2009, B113, 6378-6396, https://doi.org/10.1021/jp810292n.

45. Ugliengo, P. Moldraw Program. University of Torino, Dipartimento Chimica IFM, Torino, Italy, 1998.

46. Glendening, E.D.; Badenhoop, J.K.; Reed, A.D.; Carpenter, J.E.; Weinhold, F. NBO 3.1; Theoretical Chemistry Institute, University of Wisconsin. Madison, WI. 1996.

47. Biegler-Köning, F.; Schönbohm, J.; Bayles, D. AIM2000; A Program to Analyze and Visualize Atoms in Molecules. J. Comput. Chem. 2001, 22, 545, http://dx.doi.org/10.1002/1096987X(20010415)22:5<545::AID-JCC1027>3.0.CO;2-Y.

48. Bader, R.F.W. Atoms in Molecules, A Quantum Theory. Oxford University Press, Oxford, 1990.

49. Parr, R.G.; Pearson, R.G. Absolute hardness: companion parameter to absolute electronegativity. J. Am. Chem. Soc. 1983, 105, 7512-7516, https://doi.org/10.1021/ja00364a005.

50. Ben M'leh, C.; Brandán, S.A.; Issaoui, N.; Roisnel, T.; Marouani, H. Synthesis and physic-chemical properties of a novel chromate compound with potential biological applications, bis(2phenylethylammonium) chromate(VI). J Mol. Struct. 2019, $\quad$ 1185, 168-182, https://doi.org/10.1016/j.molstruc.2019.02.106.

51. Ruiz Hidalgo, J.; Neske, A.; Iramain, M.A.; Alvarez, P.E.; Leyton Bongiorno, P.; Brandán, S.A. FT-IR, FTRaman and UV-visible spectra of motrilin acetogenin isolated from Annona cherimolia. J Mol. Struct. 2019, 1196, 508-517, https://doi.org/10.1016/j.molstruc.2019.06.107.

52. Kausteklis, J.; Aleksa, V.; Iramain, M.A.; Brandán, S.A. Cation-anion interactions in 1-buthyl-3-methyl imidazolium nitrate ionic liquid and their effect on their structural and vibrational properties. J Mol. Struct. 2018, 1164, 1-14, https://doi.org/10.1016/j.molstruc.2018.03.100.

53. Kausteklis, J.; Aleksa, V.; Iramain, M.A.; Brandán, S.A. DFT study and vibrational assignment of 1-Butyl3-methylimidazolium trifluoromethanesulfonate ionic liquid by using the FT-Raman spectrum. J Mol. Struct. 2019, 1175, 663-676, https://doi.org/10.1016/j.molstruc.2018.08.014.

54. Rudyk, R.A.; Checa, M.A.; Catalán, C.A.N.; Brandán, S.A. Structural, FT-IR, FT-Raman and ECD studies on the free base, cationic and hydrobromide species of scopolamine alkaloid. J Mol. Struct. 2019, 1180, 603617, https://doi.org/10.1016/j.molstruc.2018.12.040.

55. Romani, D.; Brandán, S.A. Investigating the behaviors of corticosterone hormone in different solvents by using DFT calculations and experimental data, Biointerface Research in Applied Chemistry, 2020, 10(1), 4876-4892. https://doi.org/10.33263/BRIAC101.876892

56. Márquez, M.J.; Brandán, S.A. DFT study of Species Derived from the Narcotic Antagonist Naloxone, Biointerface Research in Applied Chemistry, 2020, 10(2), 8096-8116. https://doi.org/10.33263/BRIAC102.096116.

57. Hsu, K.C.; Chen, Y.F.; Lin, S.R.; Yang, J.M. iGEMDOCK: a graphical environment of enhancing GEMDOCK using pharmacological interactions and post-screening analysis. BMC Bioinformatics 2011, 12 Suppl 1, S33, https://doi.org/10.1186/1471-2105-12-s1-s33.

58. Yang, J.M.; Chen, C.C. GEMDOCK: a generic evolutionary method for molecular docking. Proteins 2004, 55, 288-304, https://doi.org/10.1002/prot.20035.

59. Visualizer, D.S. Accelrys software inc. Discovery Studio Visualizer 2, 2005.

60. Veber. D.F.; Johnson, S.R.; Cheng, H-Y, Brian, R.; Ward, K.W.; Kopple, K.D. Molecualr Properties that influence the oral bioavailability of drug candidates. J. Med. Chem. 2002, 45, 2615-2623, https://doi.org/10.1021/jm020017n.

61. Lipinski, C.A.; Lombardo, F.; Dominy, B.W.; Feeney, P.J. Experimental and computational approaches to estimate solubility and permeability in drug discovery and development setting, Advanced Drug Delivery Reviews, 2001, 46, 3-26.

62. Experimental available ATR Niclosamide from: https://spectrabase.com/spectrum/

63. Keresztury, G.; Holly, S.; Besenyei, G.; Varga, J.; Wang, A.; Durig, J.R. Vibrational spectra of monothiocarbamates-II. IR and Raman spectra, vibrational assignment, conformational analysis and ab initio calculations of S-methyl-N,N-dimethylthiocarbamate. Spectrochimica Acta Part A: Molecular Spectroscopy 1993, 49, 2007-2026, https://doi.org/10.1016/S0584-8539(09)91012-1.

64. Michalska, D.; Wysokiński, R. The prediction of Raman spectra of platinum(II) anticancer drugs by density functional theory. Chemical Physics Letters 2005, 403, 211-217, https://doi.org/10.1016/j.cplett.2004.12.096.

65. Castillo, M.V.; Rudyk, R.A.; Davies, L.; Brandán, S.A. Analysis of the structure and the FT-IR and Raman spectra of 2-(4-nitrophenyl)-4H-3,1-benzoxazin-4-one. Comparisons with the chlorinated and methylated derivatives. Journal of Molecular Structure 2017, 1140, 2-11, http://dx.doi.org/10.1016/j.molstruc.2016.08.070.

66. Wu, C.J.; Jan, J.T.; Chen, C.M.; Hsieh, H.P.; Hwang, D.R.; Liu, H.W.; Liu, C.Y.; Huang, H.W.; Chen, S.C.; Hong, C.F.; Lin, R.K.; Chao, Y.S.; Hsu, J.T. Inhibition of severe acute respiratory syndrome coronavirus replication by niclosamide. Antimicrob Agents Chemother 2004, 48, 2693-2696, https://doi.org/10.1128/aac.48.7.2693-2696.2004. 
67. Jin, Z.; Du, X.; Xu, Y. Structure of Mpro from COVID-19 virus and discovery of its inhibitors. Bio Rxiv. 2020.

68. Onur, F.; Tekin, N. Spectrophotometric Determination of Niclosamide and Thiabendazole in Tablets. Analytical Letters 1994, 27, 2291-2301, https://doi.org/10.1080/00032719408005983.

69. Othman, N.; Sultan, S. Spectrophotometric Determination of Niclosamide by Prior Reduction and Subsequent Diazotization-Coupling with 2,6-Dihydroxybenzoic acid-Application to Tablets. 2018, 25, 4052.

70. Shantier, S.; Garelnabi, E.; Gadkariem, E. Stability studies on niclosamide using derivative spectroscopic and chromatographic methods. World Journal of Pharmaceutical Research 2015, 4, 122-132.

71. Shantier, S.W.; Elobaid, E.A.; Gadkariem, E.A. Development of derivative spectrophotometric and HPLC methods for determination of niclosamide. J. Harmonized research (JOHR) 2015, 4, 87-92. 


\section{Supplementary files}

Table S1. Comparison of calculated geometrical parameters for the conformer C2 of niclosamide in gas and chloroform, ethanol and water solutions compared with the corresponding experimental ones in the solid phase.

\begin{tabular}{|c|c|c|c|c|c|}
\hline \multicolumn{6}{|c|}{ B3LYP/6-31G*a } \\
\hline Parameters & Gas & Chloroform & Ethanol & Water & $\operatorname{Exp}^{b}$ \\
\hline \multicolumn{6}{|c|}{ Bond lengths $(\AA)$} \\
\hline $\mathrm{C} 11-\mathrm{O} 4$ & 1.240 & 1.242 & 1.243 & 1.244 & \\
\hline $\mathrm{C} 14-\mathrm{O} 3$ & 1.339 & 1.343 & 1.347 & 1.353 & 1.331 \\
\hline N7-C9 & 1.396 & 1.394 & 1.393 & 1.393 & 1.395 \\
\hline N7-C11 & 1.379 & 1.376 & 1.376 & 1.375 & 1.361 \\
\hline C10-C11 & 1.483 & 1.484 & 1.484 & 1.483 & 1.540 \\
\hline C12-Cl1 & 1.761 & 1.762 & 1.761 & 1.760 & 1.730 \\
\hline $\mathrm{C} 20-\mathrm{Cl} 2$ & 1.757 & 1.764 & 1.765 & 1.764 & 1.737 \\
\hline C15-N8 & 1.466 & 1.458 & 1.453 & 1.451 & 1.462 \\
\hline $\mathrm{N} 8-\mathrm{O} 5$ & 1.230 & 1.233 & 1.235 & 1.236 & 1.220 \\
\hline N8-O6 & 1.231 & 1.233 & 1.235 & 1.236 & 1.219 \\
\hline RMSD & 0.024 & 0.025 & 0.026 & 0.026 & \\
\hline \multicolumn{6}{|c|}{ Bond angles $\left({ }^{\circ}\right)$} \\
\hline N7-C11-O4 & 121.6 & 121.6 & 121.6 & 121.6 & \\
\hline N7-C11-C10 & & 117.1 & 117.0 & 117.1 & \\
\hline C10-C11-O4 & 121.5 & 121.2 & 121.2 & 121.2 & \\
\hline C10-C14-O3 & 123.4 & 123.2 & 123.1 & 123.0 & \\
\hline C19-C14-O3 & 117.1 & 117.1 & 117.0 & 117.0 & 111.1 \\
\hline C9-N7-C11 & 129.0 & 128.7 & 128.6 & 128.6 & 129.1 \\
\hline C15-N8-O5 & 117.5 & 117.9 & 118.3 & 118.3 & 118.1 \\
\hline C15-N8-O6 & 117.6 & 118.1 & 118.4 & 118.5 & 118.5 \\
\hline O6-N8-O5 & 124.8 & 123.8 & 123.2 & 123.0 & 123.2 \\
\hline N8-C15-C17 & 118.7 & 118.7 & 118.8 & 118.7 & 118.2 \\
\hline N8-C15-C18 & 119.7 & 119.6 & 119.6 & 119.6 & 119.3 \\
\hline C11-C12-C9 & 119.9 & 120.1 & 120.1 & 120.2 & 119.3 \\
\hline $\mathrm{C} 11-\mathrm{C} 12-\mathrm{C} 17$ & 118.2 & 118.0 & 117.9 & 117.8 & 118.0 \\
\hline Cl2-C20-C16 & 119.7 & 119.5 & 119.4 & 119.4 & 119.5 \\
\hline $\mathrm{Cl} 2-\mathrm{C} 20-\mathrm{C} 21$ & 119.6 & 119.4 & 119.3 & 119.3 & 119.3 \\
\hline RMSD & 1.9 & 1.9 & 1.8 & 1.8 & \\
\hline \multicolumn{6}{|c|}{ Dihedral angles $\left({ }^{\circ}\right)$} \\
\hline C9-N7-C11-O4 & -3.1 & -3.2 & -3.5 & -2.84 & \\
\hline C9-N7-C11-C10 & 177.8 & 177.7 & 177.5 & 178.3 & \\
\hline N7-C9-C12-Cl1 & -0.4 & -1.1 & -1.0 & -0.9 & -3.6 \\
\hline O6-N8-C15-C18 & 179.9 & -179.0 & 179.1 & 178.4 & 179.9 \\
\hline N7-C11- C10-C14 & 167.7 & 168.5 & 167.3 & 167.6 & \\
\hline C11-C10-C14-O3 & 2.1 & 1.5 & 1.5 & 1.5 & \\
\hline $\mathrm{Cl} 2-\mathrm{C} 20-\mathrm{C} 16-\mathrm{C} 10$ & 179.6 & 179.6 & 179.6 & 179.7 & 177.8 \\
\hline O4-C11-C10-C14 & -11.3 & -10.5 & -11.5 & -11.1 & \\
\hline RMSD & 2.1 & 207.2 & 1.9 & 2.1 & \\
\hline
\end{tabular}

This work, ${ }^{b} \operatorname{Ref}[37]$. 
Table S2. Mulliken, Merz-Kollman and NPA charges (a.u.), molecular electrostatic potentials (MEP) (a.u.) and bond orders, expressed as Wiberg indexes of two conformers of antiviral Niclosamide in different media by using B3LYP/6-31G* level of theory.

\begin{tabular}{|c|c|c|c|c|c|c|c|c|}
\hline \multicolumn{9}{|c|}{ Conformer C1 } \\
\hline \multicolumn{5}{|c|}{ MK } & \multicolumn{4}{|c|}{ Mulliken } \\
\hline Atoms & gas & Chloroform & Ethanol & Water & gas & Chloroform & Ethanol & Water \\
\hline $1 \mathrm{Cl}$ & -0.065 & -0.064 & -0.063 & -0.062 & 0.000 & 0.000 & 0.000 & 0.000 \\
\hline $2 \mathrm{Cl}$ & -0.072 & -0.075 & -0.080 & -0.074 & -0.006 & -0.009 & -0.010 & -0.009 \\
\hline $3 \mathrm{O}$ & -0.562 & -0.577 & -0.569 & -0.555 & -0.671 & -0.671 & -0.670 & -0.672 \\
\hline $4 \mathrm{O}$ & -0.490 & -0.489 & -0.489 & -0.496 & -0.507 & -0.509 & -0.511 & -0.513 \\
\hline $5 \mathrm{O}$ & -0.393 & -0.391 & -0.397 & -0.397 & -0.395 & -0.396 & -0.397 & -0.396 \\
\hline 60 & -0.393 & -0.390 & -0.397 & -0.397 & -0.399 & -0.400 & -0.400 & -0.400 \\
\hline $7 \mathrm{~N}$ & -0.475 & -0.485 & -0.452 & -0.451 & -0.805 & -0.806 & -0.803 & -0.805 \\
\hline $8 \mathrm{~N}$ & 0.652 & 0.640 & 0.654 & 0.654 & 0.376 & 0.368 & 0.362 & 0.360 \\
\hline \multicolumn{5}{|c|}{$\mathrm{BO}$} & \multicolumn{4}{|c|}{ MEP } \\
\hline Atoms & gas & Chloroform & Ethanol & Water & gas & Chloroform & Ethanol & Water \\
\hline $1 \mathrm{Cl}$ & 1.219 & 1.218 & 1,218 & 1,219 & -64.349 & -64.349 & -64.348 & -64.348 \\
\hline $2 \mathrm{Cl}$ & 1.200 & 1.194 & 1,193 & 1,194 & -64.364 & -64.364 & -64.364 & -64.364 \\
\hline $3 \mathrm{O}$ & 1.931 & 1.936 & 1,937 & 1,936 & -22.229 & -22.227 & -22.226 & -22.226 \\
\hline $4 \mathrm{O}$ & 2.004 & 2.002 & 1,998 & 1,996 & -22.322 & -22.323 & -22.324 & -22.324 \\
\hline $5 \mathrm{O}$ & 2.041 & 2.037 & 2,034 & 2,033 & -22.292 & -22.294 & -22.296 & -22.296 \\
\hline 60 & 2.036 & 2.032 & 2,029 & 2,028 & -22.293 & -22.294 & -22.295 & -22.296 \\
\hline $7 \mathrm{~N}$ & 3.251 & 3.253 & 3,254 & 3,255 & -18.282 & -18.282 & -18.282 & -18.282 \\
\hline $8 \mathrm{~N}$ & 3.974 & 3.973 & 3,973 & 3,972 & -18.109 & -18.111 & -18.112 & -18.112 \\
\hline \multicolumn{9}{|c|}{ Conformer C2 } \\
\hline \multicolumn{5}{|c|}{ MK } & \multicolumn{4}{|c|}{ Mulliken } \\
\hline Atoms & gas & Chloroform & Ethanol & Water & gas & Chloroform & Ethanol & Water \\
\hline $1 \mathrm{Cl}$ & -0.036 & -0.035 & -0.034 & -0.034 & 0.016 & 0.016 & 0.017 & 0.017 \\
\hline $2 \mathrm{Cl}$ & -0.082 & -0.090 & -0.090 & -0.089 & -0.012 & -0.016 & -0.016 & -0.016 \\
\hline 30 & -0.564 & -0.564 & -0.563 & -0.564 & -0.641 & -0.643 & -0.645 & -0.647 \\
\hline $4 \mathrm{O}$ & -0.541 & -0.541 & -0.539 & -0.538 & -0.568 & -0.570 & -0.568 & -0.569 \\
\hline $5 \mathrm{O}$ & -0.396 & -0.395 & -0.390 & -0.390 & -0.392 & -0.392 & -0.392 & -0.392 \\
\hline 60 & -0.398 & -0.396 & -0.390 & -0.390 & -0.395 & -0.395 & -0.395 & -0.395 \\
\hline $7 \mathrm{~N}$ & -0.514 & -0.515 & -0.513 & -0.504 & -0.768 & -0.765 & -0.763 & -0.764 \\
\hline $8 \mathrm{~N}$ & 0.686 & 0.678 & 0.654 & 0.652 & 0.379 & 0.370 & 0.364 & 0.362 \\
\hline \multicolumn{5}{|c|}{$\mathrm{BO}$} & \multicolumn{4}{|c|}{ MEP } \\
\hline Atoms & gas & Chloroform & Ethanol & Water & gas & Chloroform & Ethanol & Water \\
\hline $1 \mathrm{Cl}$ & 1.227 & 1.225 & 1,226 & 1,226 & -64.336 & -64.336 & -64.336 & -64.336 \\
\hline $2 \mathrm{Cl}$ & 1.194 & 1.189 & 1,188 & 1,189 & -64.361 & -64.362 & -64.362 & -64.361 \\
\hline $3 \mathrm{O}$ & 1.975 & 1.972 & 1,969 & 1,965 & -22.272 & -22.273 & -22.273 & -22.275 \\
\hline $4 \mathrm{O}$ & 1.985 & 1.985 & 1,984 & 1,984 & -22.296 & -22.296 & -22.296 & -22.296 \\
\hline $5 \mathrm{O}$ & 2.046 & 2.042 & 2,039 & 2,038 & -22.283 & -22.285 & -22.286 & -22.286 \\
\hline 60 & 2.042 & 2.038 & 2,035 & 2,034 & -22.284 & -22.285 & -22.286 & -22.286 \\
\hline $7 \mathrm{~N}$ & 3.262 & 3.263 & 3,263 & 3,264 & -18.260 & -18.258 & -18.258 & -18.257 \\
\hline $8 \mathrm{~N}$ & 3.975 & 3.974 & 3,973 & 3,973 & -18.100 & -18.101 & -18.102 & -18.103 \\
\hline
\end{tabular}


Table S3. Main delocalization energies (in $\mathrm{kJ} / \mathrm{mol}$ ) of conformer $\mathrm{C} 1$ of antiviral Niclosamide in different media by using B3LYP/6-31G* calculations.

\begin{tabular}{|c|c|c|c|c|}
\hline \multicolumn{5}{|c|}{ B3LYP/6-31G*a } \\
\hline \multicolumn{5}{|c|}{ Conformer C1 } \\
\hline Delocalization & gas & Chloroform & Ethanol & Water \\
\hline$\pi C 9-C 12 \rightarrow \pi^{*} C 13-C 18$ & 59.02 & 58.69 & 58.52 & 58.56 \\
\hline$\pi C 9-C 12 \rightarrow \pi^{*} C 15-C 17$ & 101.95 & 102.91 & 103.50 & 103.50 \\
\hline$\pi C 10-C 16 \rightarrow \pi * O 4-C 11$ & 90.46 & 92.46 & 93.51 & 94.64 \\
\hline$\pi C 10-C 16 \rightarrow \pi^{*} C 14-C 19$ & 105.67 & 105.67 & 105.13 & 105.25 \\
\hline$\pi C 10-C 16 \rightarrow \pi^{*} C 20-C 21$ & 73.40 & 74.15 & 74.53 & 74.74 \\
\hline$\pi C 13-C 18 \rightarrow \pi^{*} C 9-C 12$ & 101.16 & 100.86 & 100.91 & 100.86 \\
\hline$\pi C 13-C 18 \rightarrow \pi^{*} C 15-C 17$ & 79.13 & 78.54 & 78.25 & 78.33 \\
\hline$\pi C 14-C 19 \rightarrow \pi^{*} C 10-C 16$ & 66.25 & 65.84 & 65.88 & 65.79 \\
\hline$\pi C 14-C 19 \rightarrow \pi^{*} C 20-C 21$ & 99.07 & 99.65 & 100.03 & 99.99 \\
\hline$\pi C 15-C 17 \rightarrow \pi^{*} O 5-N 8$ & 117.83 & 121.89 & 125.19 & 126.07 \\
\hline$\pi C 15-C 17 \rightarrow \pi^{*} C 9-C 12$ & 71.65 & 72.06 & 72.31 & 72.40 \\
\hline$\pi C 15-C 17 \rightarrow \pi^{*} C 13-C 18$ & 87.19 & 86.61 & 86.23 & 86.15 \\
\hline$\pi C 20-C 21 \rightarrow \pi^{*} C 10-C 16$ & 101.11 & 102.08 & 102.41 & 102.62 \\
\hline$\pi C 20-C 21 \rightarrow \pi^{*} C 14-C 19$ & 70.73 & 71.06 & 71.48 & 71.65 \\
\hline$\Delta E_{\pi \rightarrow \pi^{*}}$ & 1224.61 & 1232.47 & 1237.87 & 1240.54 \\
\hline$\pi O 5-N 8 \rightarrow L P(3) O 6$ & 50.37 & 50.37 & 50.33 & 50.16 \\
\hline$\Delta E_{\pi \rightarrow L P}$ & 50.37 & 50.37 & 50.33 & 50.16 \\
\hline$L P(3) C l 1 \rightarrow \pi^{*} C 9-C 12$ & 46.15 & 45.98 & 46.06 & 46.36 \\
\hline$L P(3) C l 2 \rightarrow \pi * C 20-C 21$ & 49.28 & 47.82 & 47.48 & 47.61 \\
\hline$L P(2) O 3 \rightarrow \pi^{*} C 14-C 19$ & 113.24 & 116.08 & 116.71 & 115.41 \\
\hline$L P(3) O 6 \rightarrow \pi^{*}(1) O 5-N 8$ & 676.99 & 673.73 & 671.14 & 669.26 \\
\hline$L P(1) N 7 \rightarrow \pi * O 4-C 11$ & 252.01 & 252.26 & 254.14 & 255.44 \\
\hline$L P(1) N 7 \rightarrow \pi^{*} C 9-C 12$ & 182.00 & 184.92 & 185.88 & 185.55 \\
\hline$\Delta E_{L P \rightarrow \pi^{*}}$ & 1319.67 & 1320.80 & 1321.42 & 1319.63 \\
\hline$L P(1) O 3 \rightarrow \sigma^{*}(1) N 7-H 22$ & 48.74 & 52.04 & 50.83 & 53.42 \\
\hline$L P(2) O 4 \rightarrow \sigma^{*}(1) N 7-C 11$ & 106.55 & 105.67 & 104.17 & 103.16 \\
\hline$L P(2) O 4 \rightarrow \sigma^{*}(1) C 10-C 11$ & 84.35 & 82.93 & 81.43 & 80.63 \\
\hline$L P(2) O 5 \rightarrow \sigma^{*}(1) O 6-N 8$ & 80.30 & 79.38 & 78.75 & 78.54 \\
\hline$L P(2) O 5 \rightarrow \sigma^{*}(1) N 8-C 15$ & 52.50 & 51.37 & 50.49 & 50.03 \\
\hline$L P(2) O 6 \rightarrow \sigma^{*}(1) O 5-N 8$ & 80.09 & 79.38 & 78.88 & 78.58 \\
\hline$L P(2) O 6 \rightarrow \sigma^{*}(1) N 8-C 15$ & 52.17 & 51.12 & 50.24 & 49.78 \\
\hline$\Delta E_{L P \rightarrow \sigma^{*}}$ & 504.69 & 501.89 & 494.79 & 494.16 \\
\hline$\pi^{*} O 4-C 11 \rightarrow \pi^{*} C 10-C 16$ & 637.37 & 657.60 & 646.40 & 639.29 \\
\hline$\pi^{*} O 5-N 8 \rightarrow \pi^{*} C 15-C 17$ & 73.11 & 76.54 & 79.17 & 79.38 \\
\hline$\pi^{*} C 9-C 12 \rightarrow \pi^{*} C 13-C 18$ & 363.79 & 355.43 & 349.32 & 349.32 \\
\hline$\pi^{* C 9-C 12 \rightarrow \pi^{*} C 15-C 17}$ & 715.66 & 724.39 & 730.29 & 730.25 \\
\hline$\pi^{*} C 14-C 19 \rightarrow \pi^{*} C 10-C 16$ & 960.44 & 941.13 & 933.19 & 932.56 \\
\hline$\pi^{*} C 15-C 17 \rightarrow \pi * C 13-C 18$ & 805.03 & 756.37 & 721.97 & 722.68 \\
\hline$\pi^{*} C 20-C 21 \rightarrow \pi^{*} C 10-C 16$ & 1077.10 & 1136.12 & 1167.31 & 1177.26 \\
\hline$\Delta E_{\pi^{*} \rightarrow \pi^{*}}$ & 4632.49 & 4647.57 & 4627.64 & 4630.73 \\
\hline$\Delta E_{\text {Total }}$ & 7731.83 & 7753.11 & 7732.04 & 7735.22 \\
\hline
\end{tabular}

aThis work 
Table S4. Main delocalization energies (in $\mathrm{kJ} / \mathrm{mol}$ ) of conformer $\mathrm{C} 2$ of antiviral Niclosamide in different media by using B3LYP/6-31G* calculations.

\begin{tabular}{|c|c|c|c|c|}
\hline \multicolumn{5}{|c|}{ B3LYP/6-31G*a } \\
\hline \multicolumn{5}{|c|}{ Conformer C2 } \\
\hline Delocalization & gas & Chloroform & Ethanol & Water \\
\hline$\pi C 9-C 13 \rightarrow \pi^{*} C 12-C 17$ & 73.74 & 73.57 & 73.23 & 73.23 \\
\hline$\pi C 9-C 13 \rightarrow \pi * C 15-C 18$ & 100.40 & 101.03 & 101.57 & 101.53 \\
\hline$\pi C 10-C 16 \rightarrow \pi^{*} O 4-C 11$ & 112.57 & 112.94 & 112.11 & 112.44 \\
\hline$\pi C 10-C 16 \rightarrow \pi^{*} C 20-C 21$ & 66.71 & 67.09 & 67.34 & 67.59 \\
\hline$\pi C 12-C 17 \rightarrow \pi^{*} C 9-C 13$ & 81.72 & 81.34 & 81.13 & 81.05 \\
\hline$\pi C 12-C 17 \rightarrow \pi^{*} C 15-C 18$ & 63.41 & 63.24 & 62.99 & 62.99 \\
\hline$\pi C 15-C 18 \rightarrow \pi^{*} O 5-N 8$ & 104.58 & 108.47 & 111.65 & 112.48 \\
\hline$\pi C 15-C 18 \rightarrow \pi^{*} C 9-C 13$ & 74.61 & 75.62 & 76.03 & 76.12 \\
\hline$\pi C 15-C 18 \rightarrow \pi^{*} C 12-C 17$ & 106.84 & 106.09 & 105.67 & 105.50 \\
\hline$\pi C 20-C 21 \rightarrow \pi^{*} C 10-C 16$ & 108.39 & 107.64 & 107.01 & 106.88 \\
\hline$\Delta E_{\pi \rightarrow \pi^{*}}$ & 892.97 & 897.03 & 898.74 & 899.83 \\
\hline$\pi O 5-N 8 \rightarrow L P(3) O 6$ & 50.83 & 50.87 & 50.83 & 50.70 \\
\hline$\pi C 20-C 21 \rightarrow L P(1) C 19$ & 176.61 & 175.85 & 175.56 & 175.56 \\
\hline$\Delta E_{\pi \rightarrow L P}$ & 227.43 & 226.72 & 226.39 & 226.26 \\
\hline$\pi C 10-C 16 \rightarrow L P(1)^{*} C 14$ & 223.96 & 222.50 & 222.25 & 222.21 \\
\hline$\Delta E_{\pi \rightarrow L P} *$ & 223.96 & 222.50 & 222.25 & 222.21 \\
\hline$L P(3) C l 1 \rightarrow \pi^{*} C 12-C 17$ & 46.15 & 45.85 & 46.02 & 46.11 \\
\hline$L P(3) C l 2 \rightarrow \pi^{*} C 20-C 21$ & 46.36 & 45.14 & 45.02 & 45.14 \\
\hline$L P(3) O 6 \rightarrow \pi * O 5-N 8$ & 681.88 & 678.58 & 675.86 & 674.15 \\
\hline$L P(1) N 7 \rightarrow \pi^{*} O 4-C 11$ & 261.12 & 263.67 & 262.13 & 264.59 \\
\hline$L P(1) N 7 \rightarrow \pi^{*} C 9-C 13$ & 161.31 & 159.68 & 159.84 & 159.76 \\
\hline$L P(1) C 14 \rightarrow \pi^{*} C 10-C 16$ & 270.20 & 270.74 & 271.95 & 273.16 \\
\hline$L P(1) C 19 \rightarrow \pi^{*} C 20-C 21$ & 403.58 & 399.40 & 396.89 & 396.43 \\
\hline$\Delta E_{L P \rightarrow \pi^{*}}$ & 1870.59 & 1863.07 & 1857.72 & 1859.35 \\
\hline$L P(2) O 4 \rightarrow \sigma^{*}(1) O 3-H 29$ & 84.39 & 90.12 & 85.69 & 87.45 \\
\hline$L P(2) O 4 \rightarrow \sigma^{*}(1) N 7-C 11$ & 101.70 & 100.15 & 100.36 & 99.69 \\
\hline$L P(2) O 4 \rightarrow \sigma^{*}(1) C 10-C 11$ & 51.87 & 50.24 & 50.75 & 50.16 \\
\hline$L P(2) O 5 \rightarrow \sigma^{*}(1) O 6-N 8$ & 80.26 & 79.38 & 78.75 & 78.50 \\
\hline$L P(2) O 5 \rightarrow \sigma^{*}(1) N 8-C 15$ & 53.38 & 52.29 & 51.37 & 50.91 \\
\hline$L P(2) O 6 \rightarrow \sigma^{*}(1) O 5-N 8$ & 80.17 & 79.42 & 78.88 & 78.58 \\
\hline$L P(2) O 6 \rightarrow \sigma^{*}(1) N 8-C 15$ & 53.13 & 52.04 & 51.16 & 50.70 \\
\hline$\Delta E_{L P \rightarrow \sigma^{*}}$ & 504.90 & $\mathbf{5 0 3 . 6 5}$ & 496.96 & 496.00 \\
\hline$L P(2) O 3 \rightarrow L P(1) * C 14$ & 308.94 & 307.73 & 301.59 & 295.78 \\
\hline$\Delta E_{L P \rightarrow L P *}$ & 308.94 & 307.73 & 301.59 & 295.78 \\
\hline$\pi^{*} 04-C 11 \rightarrow \pi^{*} C 10-C 16$ & 439.03 & 418.46 & 419.13 & 412.82 \\
\hline$\pi^{*} O 5-N 8 \rightarrow \pi^{*} C 15-C 18$ & 79.96 & 83.39 & 85.94 & 86.28 \\
\hline$\pi^{*} C 12-C 17 \rightarrow \pi^{*} C 15-C 18$ & 1003.41 & 1045.59 & 1079.44 & 1084.38 \\
\hline$\Delta E_{\pi^{*} \rightarrow \pi^{*}}$ & 1522.40 & 1547.44 & 1584.51 & 1583.47 \\
\hline$\Delta E_{\text {Total }}$ & 5551.19 & 5568.14 & 5588.16 & 5582.9 \\
\hline
\end{tabular}

aThis work 
Table S5. Analysis of the Bond Critical Points (BCPs) and Ring critical point (RCPs) of conformer $\mathrm{C} 1$ of antiviral Niclosamide in different media by using the B3LYP/6-31G* method.

\begin{tabular}{|c|c|c|c|c|c|c|c|c|}
\hline \multicolumn{9}{|c|}{ B3LYP/6-31G* Method } \\
\hline \multicolumn{9}{|c|}{ GAS PHASE } \\
\hline Parameter ${ }^{\#}$ & $\mathrm{O} 4-\mathrm{H} 23$ & RCPN1 & $\mathrm{O} 3-\mathrm{H} 22$ & RCPN2 & $\mathrm{H} 22-\mathrm{Cl1}$ & RCPN3 & RCP1 & $\mathrm{RCP} 2$ \\
\hline$\rho(r)$ & 0.0219 & 0.0127 & 0.0306 & 0.0121 & 0.0159 & 0.0151 & 0.0199 & 0.0199 \\
\hline$\nabla^{2} \rho(\mathrm{r})$ & 0.0776 & 0.0727 & 0.1119 & 0.0772 & 0.0664 & 0.0820 & 0.1564 & 0.1569 \\
\hline$\lambda 1$ & -0.0253 & -0.0097 & -0.0426 & -0.0090 & -0.0154 & -0.0125 & -0.0147 & -0.0148 \\
\hline$\lambda 2$ & -0.0226 & 0.0265 & -0.0413 & 0.0371 & -0.0100 & 0.0145 & 0.0806 & 0.0797 \\
\hline$\lambda 3$ & 0.1255 & 0.0559 & 0.1958 & 0.0491 & 0.0918 & 0.0799 & 0.0903 & 0.0919 \\
\hline$|\lambda 1| / \lambda 3$ & 0.2016 & 0.1735 & 0.2176 & 0.1833 & 0.1678 & 0.1564 & 0.1628 & 0.1610 \\
\hline Distances & 2.117 & & 1.870 & & 2.445 & & & \\
\hline \multicolumn{9}{|c|}{ CHLOFORORM } \\
\hline Parameter ${ }^{\#}$ & $\mathrm{O} 4-\mathrm{H} 23$ & RCPN1 & $\mathrm{O} 3-\mathrm{H} 22$ & RCPN2 & $\mathrm{H} 22-\mathrm{Cl1}$ & RCPN3 & RCP1 & RCP2 \\
\hline$\rho(r)$ & 0.0214 & 0.0126 & 0.0319 & 0.0124 & 0.0159 & 0.0151 & 0.0199 & 0.0199 \\
\hline$\nabla^{2} \rho(r)$ & 0.0757 & 0.0717 & 0.1172 & 0.0795 & 0.0663 & 0.0817 & 0.1560 & 0.1564 \\
\hline$\lambda 1$ & -0.0246 & -0.0096 & -0.0453 & -0.0094 & -0.0153 & -0.0124 & -0.0147 & -0.0148 \\
\hline$\lambda 2$ & -0.0218 & 0.0258 & -0.0438 & 0.0381 & -0.0098 & 0.0142 & 0.0803 & 0.0799 \\
\hline$\lambda 3$ & 0.1221 & 0.0554 & 0.2063 & 0.0508 & 0.0915 & 0.0798 & 0.0903 & 0.0913 \\
\hline$|\lambda 1| / \lambda 3$ & 0.2015 & 0.1733 & 0.2196 & 0.1850 & 0.1672 & 0.1554 & 0.1628 & 0.1621 \\
\hline Distances & 2.130 & & 1.851 & & 2.448 & & & \\
\hline \multicolumn{9}{|c|}{ ETHANOL } \\
\hline Parameter ${ }^{\#}$ & $\mathrm{O} 4-\mathrm{H} 23$ & RCPN1 & $\mathrm{O} 3-\mathrm{H} 22$ & RCPN2 & $\mathrm{H} 22-\mathrm{Cl1}$ & RCPN3 & RCP1 & RCP2 \\
\hline$\rho(r)$ & 0.0211 & 0.0125 & 0.0322 & 0.0126 & 0.0159 & 0.0151 & 0.0199 & 0.0198 \\
\hline$\nabla^{2} \rho(\mathrm{r})$ & 0.0747 & 0.0711 & 0.1179 & 0.0810 & 0.0663 & 0.0817 & 0.1559 & 0.1562 \\
\hline$\lambda 1$ & -0.0241 & -0.0095 & -0.0460 & -0.0094 & -0.0152 & -0.0124 & -0.0146 & -0.0147 \\
\hline$\lambda 2$ & -0.0212 & 0.0254 & -0.0441 & 0.0386 & -0.0098 & 0.0142 & 0.0803 & 0.0798 \\
\hline$\lambda 3$ & 0.1200 & 0.0552 & 0.2081 & 0.0516 & 0.0914 & 0.0799 & 0.0902 & 0.0910 \\
\hline$|\lambda 1| / \lambda 3$ & 0.2008 & 0.1721 & 0.2210 & 0.1822 & 0.1663 & 0.1552 & 0.1619 & 0.1615 \\
\hline Distances & 2.139 & & 1.849 & & 2.449 & & & \\
\hline \multicolumn{9}{|c|}{ WATER } \\
\hline Parameter & $\mathrm{O} 4-\mathrm{H} 23$ & RCPN1 & $\mathrm{O} 3-\mathrm{H} 22$ & RCPN2 & H22-Cl1 & RCPN3 & RCP1 & RCP2 \\
\hline$\rho(r)$ & 0.0211 & 0.0126 & 0.0326 & 0.0126 & 0.0159 & 0.0151 & 0.0199 & 0.0198 \\
\hline$\nabla^{2} \rho(\mathrm{r})$ & 0.0750 & 0.0712 & 0.1198 & 0.0810 & 0.0664 & 0.0816 & 0.1560 & 0.1562 \\
\hline$\lambda 1$ & $-0,0242$ & $-0,0095$ & $-0,0468$ & $-0,0095$ & $-0,0152$ & $-0,0124$ & $-0,0147$ & $-0,0147$ \\
\hline$\lambda 2$ & $-0,0213$ & 0,0254 & $-0,0451$ & 0,0387 & $-0,0097$ & 0,0140 & 0,0804 & 0,0798 \\
\hline$\lambda 3$ & 0,1205 & 0,0552 & 0,2117 & 0,0517 & 0,0913 & 0,0800 & 0,0903 & 0,0910 \\
\hline$|\lambda 1| / \lambda 3$ & 0,2008 & 0,1721 & 0,2211 & 0,1838 & 0,1665 & 0,1550 & 0,1628 & 0,1615 \\
\hline Distances & 2.138 & & 1.841 & & 2.450 & & & \\
\hline
\end{tabular}

"Parameters in a.u. 
Table S6. Analysis of the Bond Critical Points (BCPs) and Ring critical point (RCPs) of conformer $\mathrm{C} 2$ of antiviral Niclosamide in different media by using the B3LYP/6-31G* method.

\begin{tabular}{|c|c|c|c|c|c|c|c|c|c|c|}
\hline \multicolumn{11}{|c|}{ B3LYP/6-31G* Method } \\
\hline \multicolumn{11}{|c|}{ GAS PHASE } \\
\hline Parameter & O4- & RCPN1 & O4- & RCPN2 & H22- & RCPN & H22- & RCPN & RCP1 & RCP2 \\
\hline$\rho(r)$ & 0.020 & 0.0121 & 0.047 & 0.0180 & 0.017 & 0.0161 & 0.013 & 0.0127 & 0.019 & 0.019 \\
\hline$\nabla^{2} \rho(r)$ & 0.072 & 0.0688 & 0.154 & 0.1160 & 0.070 & 0.0910 & 0.060 & 0.0710 & 0.156 & 0.153 \\
\hline$\lambda 1$ & - & -0.0091 & - & -0.0160 & - & -0.0134 & - & -0.0093 & - & - \\
\hline$\lambda 2$ & - & 0.0249 & - & 0.0591 & - & 0.0207 & - & 0.0113 & 0.081 & 0.079 \\
\hline$\lambda 3$ & 0.115 & 0.0529 & 0.313 & 0.0728 & 0.101 & 0.0835 & 0.083 & 0.0690 & 0.089 & 0.089 \\
\hline$|\lambda 1| / \lambda 3$ & 0.199 & 0.1720 & 0.254 & 0.2198 & 0.175 & 0.1605 & 0.168 & 0.1348 & 0.163 & 0.160 \\
\hline Distances & 2.152 & & 1.701 & & 2.395 & & 1.921 & & & \\
\hline \multicolumn{11}{|c|}{ CHLOFORORM } \\
\hline Parameter & O4- & RCPN & O4- & RCPN & $\mathrm{H} 22-$ & RCPN & H22- & RCPN & RCP1 & $\mathrm{RCP} 2$ \\
\hline$\rho(r)$ & 0.0196 & 0.0122 & 0.049 & 0.0182 & 0.0169 & 0.0155 & 0.013 & 0.0126 & 0.019 & 0.019 \\
\hline$\nabla^{2} \rho(\mathrm{r})$ & 0.0704 & 0.0686 & 0.159 & 0.1174 & 0.0674 & 0.0864 & 0.059 & 0.0704 & 0.156 & 0.154 \\
\hline$\lambda 1$ & - & -0.0087 & - & -0.0161 & - & -0.0128 & - & -0.0091 & - & - \\
\hline$\lambda 2$ & - & 0.0235 & - & 0.0603 & - & 0.0183 & - & 0.0113 & 0.081 & 0.080 \\
\hline$\lambda 3$ & 0.1113 & 0.0538 & 0.326 & 0.0732 & 0.0963 & 0.080 & 0.082 & 0.0681 & 0.089 & 0.088 \\
\hline$|\lambda 1| / \lambda 3$ & 0.1977 & 0.1617 & 0.256 & 0.2199 & 0.1724 & 0.1600 & 0.168 & 0.1336 & 0.163 & 0.161 \\
\hline Distances & 2.174 & & 1.686 & & 2.424 & & 1.922 & & & \\
\hline \multicolumn{11}{|c|}{ ETHANOL } \\
\hline Parameter & O4- & RCPN & O4- & RCPN & $\mathrm{H} 22-$ & RCPN & H22- & RCPN & RCP1 & RCP2 \\
\hline$\rho(r)$ & 0.0192 & 0.0122 & 0.048 & 0.0180 & 0.0167 & 0.0154 & 0.013 & 0.0126 & 0.019 & 0.019 \\
\hline$\nabla^{2} \rho(\mathrm{r})$ & 0.0692 & 0.0681 & 0.155 & 0.1156 & 0.0668 & 0.0854 & 0.059 & 0.0704 & 0.156 & 0.154 \\
\hline$\lambda 1$ & - & -0.0086 & - & -0.0159 & - & -0.0127 & - & -0.0090 & - & - \\
\hline$\lambda 2$ & - & 0.0228 & 0.079 & 0.0592 & - & 0.0176 & - & 0.0110 & 0.081 & 0.080 \\
\hline$\lambda 3$ & 0.1087 & 0.0538 & 0.316 & 0.0722 & 0.0950 & 0.0804 & 0.081 & 0.0683 & 0.089 & 0.088 \\
\hline$|\lambda 1| / \lambda 3$ & 0.1969 & 0.1599 & 0.255 & 0.2202 & 0.1716 & 0.1580 & 0.166 & 0.1318 & 0.163 & 0.162 \\
\hline Distances & 2.187 & & 1.698 & & 2.431 & & 1.928 & & & \\
\hline \multicolumn{11}{|c|}{ WATER } \\
\hline Parameter & O4- & $\mathrm{RCPN}$ & O4- & RCPN & H22- & RCPN & H22- & $\mathrm{RCPN}$ & RCP1 & RCP2 \\
\hline$\rho(r)$ & 0.0193 & 0.0122 & 0.048 & 0.0180 & 0.0168 & 0.0155 & 0.013 & 0.0126 & 0.019 & 0.019 \\
\hline$\nabla^{2} \rho(\mathrm{r})$ & 0.0696 & 0.0682 & 0.157 & 0.1158 & 0.0670 & 0.0860 & 0.060 & 0.0709 & 0.156 & 0.154 \\
\hline$\lambda 1$ & - & -0.0087 & - & -0.0159 & - & -0.0127 & - & -0.0092 & - & - \\
\hline$\lambda 2$ & - & 0.0230 & - & 0.0596 & - & 0.0178 & - & 0.0116 & 0.081 & 0.080 \\
\hline$\lambda 3$ & 0.1096 & 0.0539 & 0.320 & 0.0721 & 0.0955 & 0.0807 & 0.083 & 0.0685 & 0.089 & 0.088 \\
\hline$|\lambda 1| / \lambda 3$ & 0.1962 & 0.1614 & 0.255 & 0.2205 & 0.1728 & 0.1574 & 0.169 & 0.1343 & 0.163 & 0.162 \\
\hline Distances & 2.183 & & 1.692 & & 2.428 & & 1.918 & & & \\
\hline
\end{tabular}

\#Parameters in a.u. 

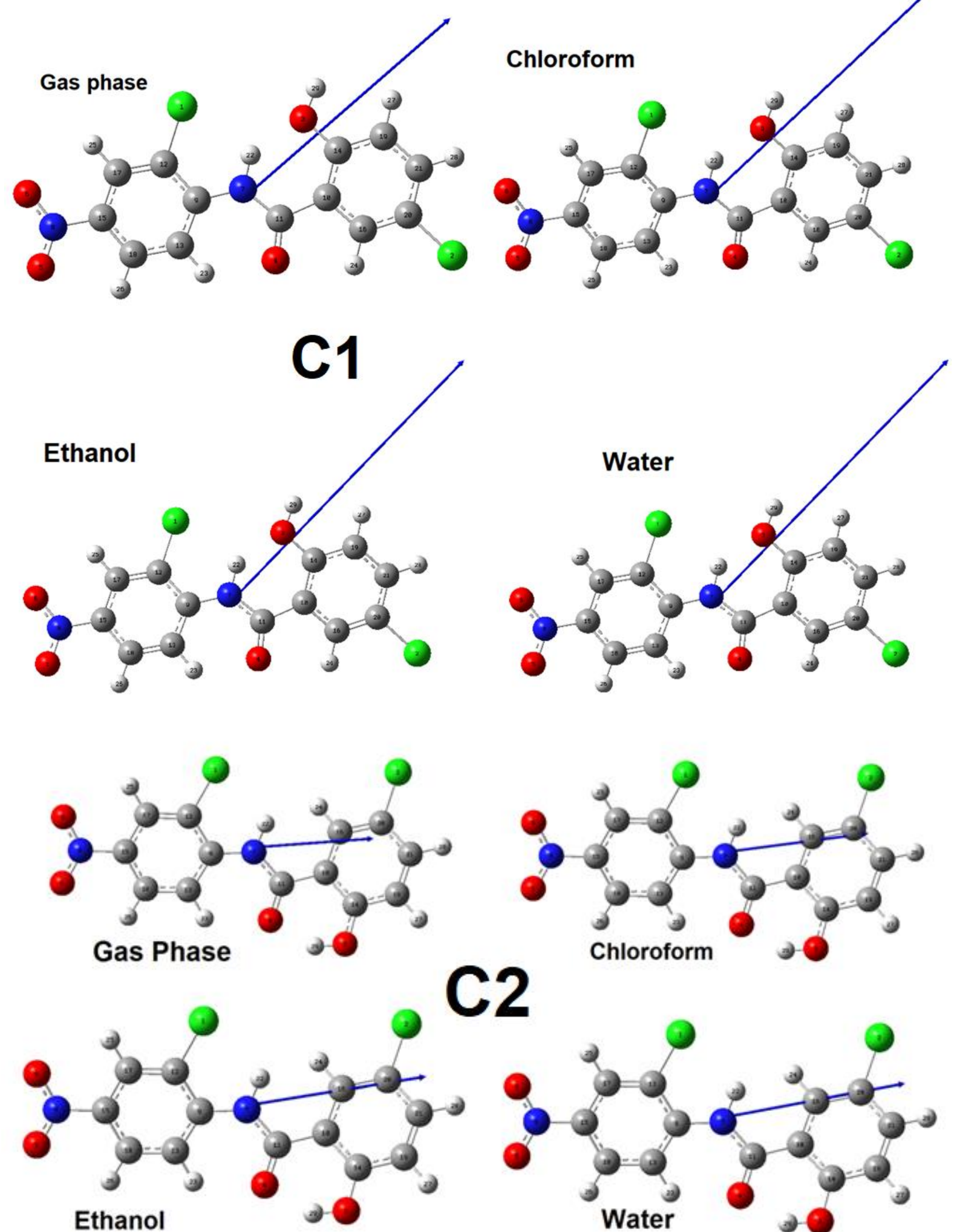

C2

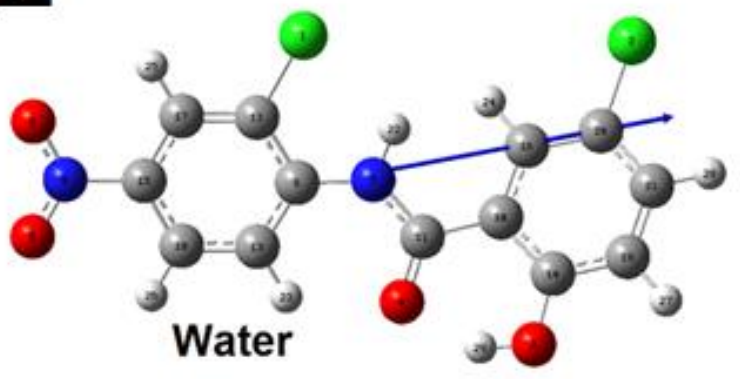

Figure S1. Magnitudes and positions of vectors of dipole moments of conformers C1 (upper) and $\mathrm{C} 2$ (bottom) of niclosamide in gas phase, chloroform, ethanol and water solvents by using the B3LYP/6-31G* method. 

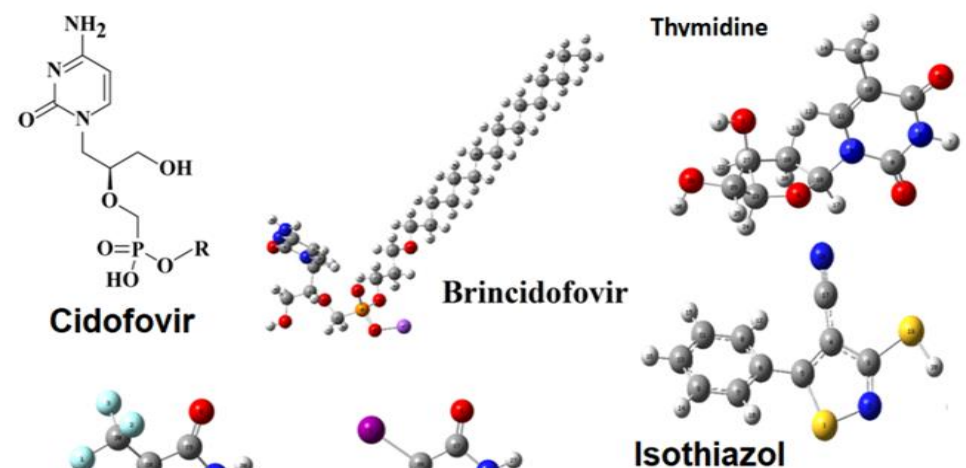

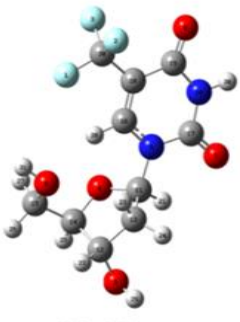

Trifluridine

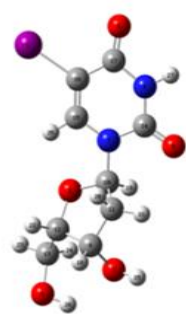

Idoxuridine

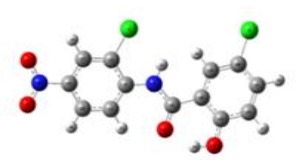

Niclosamide
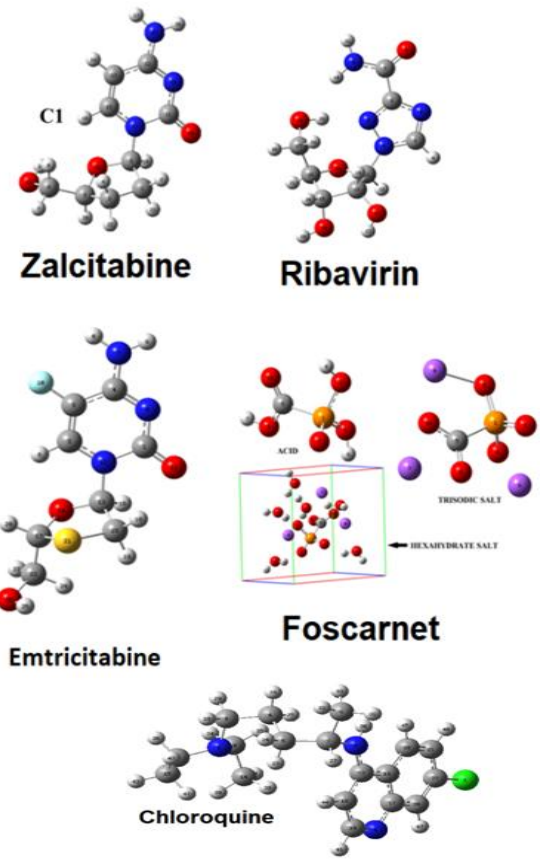

Figure S2. Molecular structures of eleven antiviral agents compared with the corresponding to most stable conformer $\mathrm{C} 2$ of niclosamide.
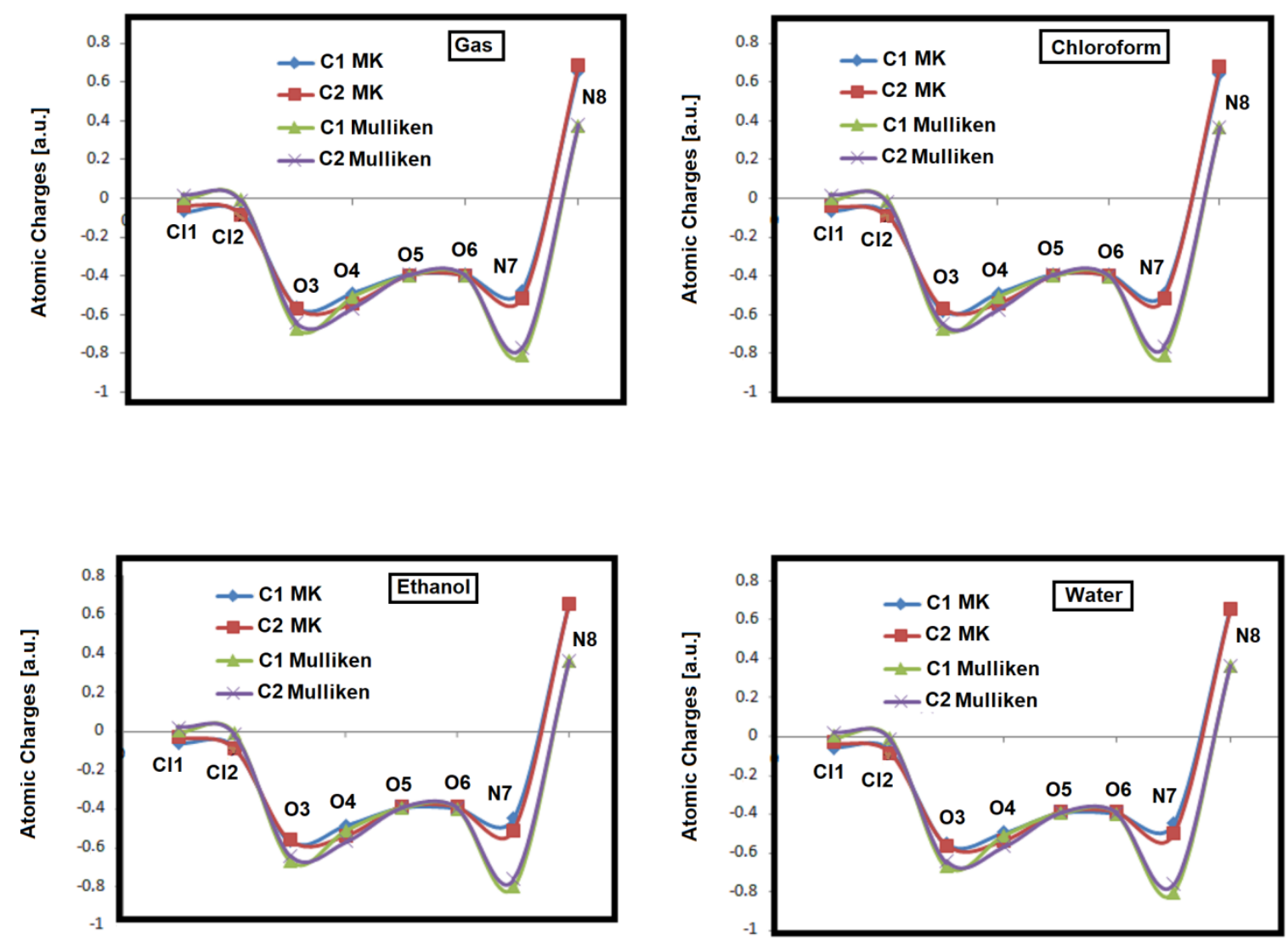

Figure S3. Variations of atomic MK and Mulliken charges of conformers $C 1$ and $C 2$ of niclosamide in gas phase, chloroform, ethanol and water solvents by using the B3LYP/6-31G* method. 


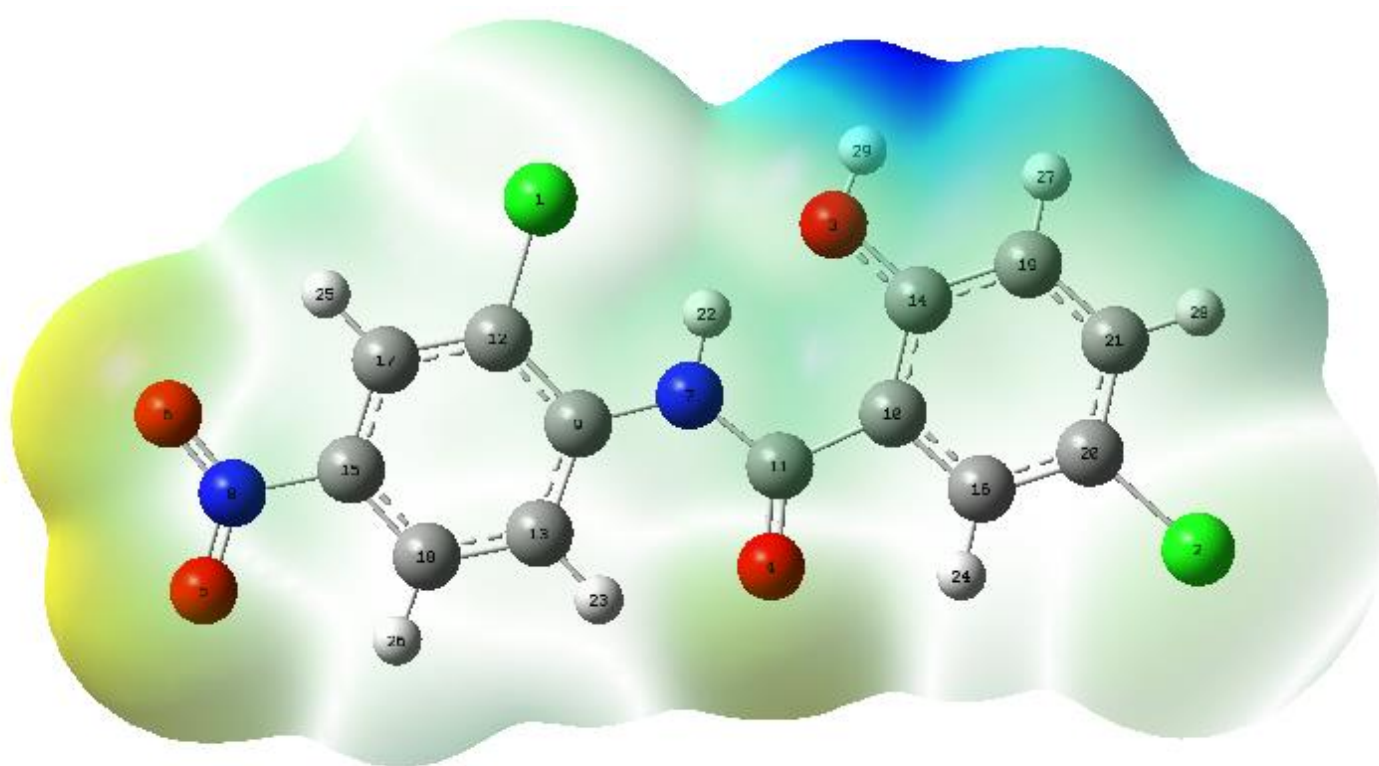

\section{C1}

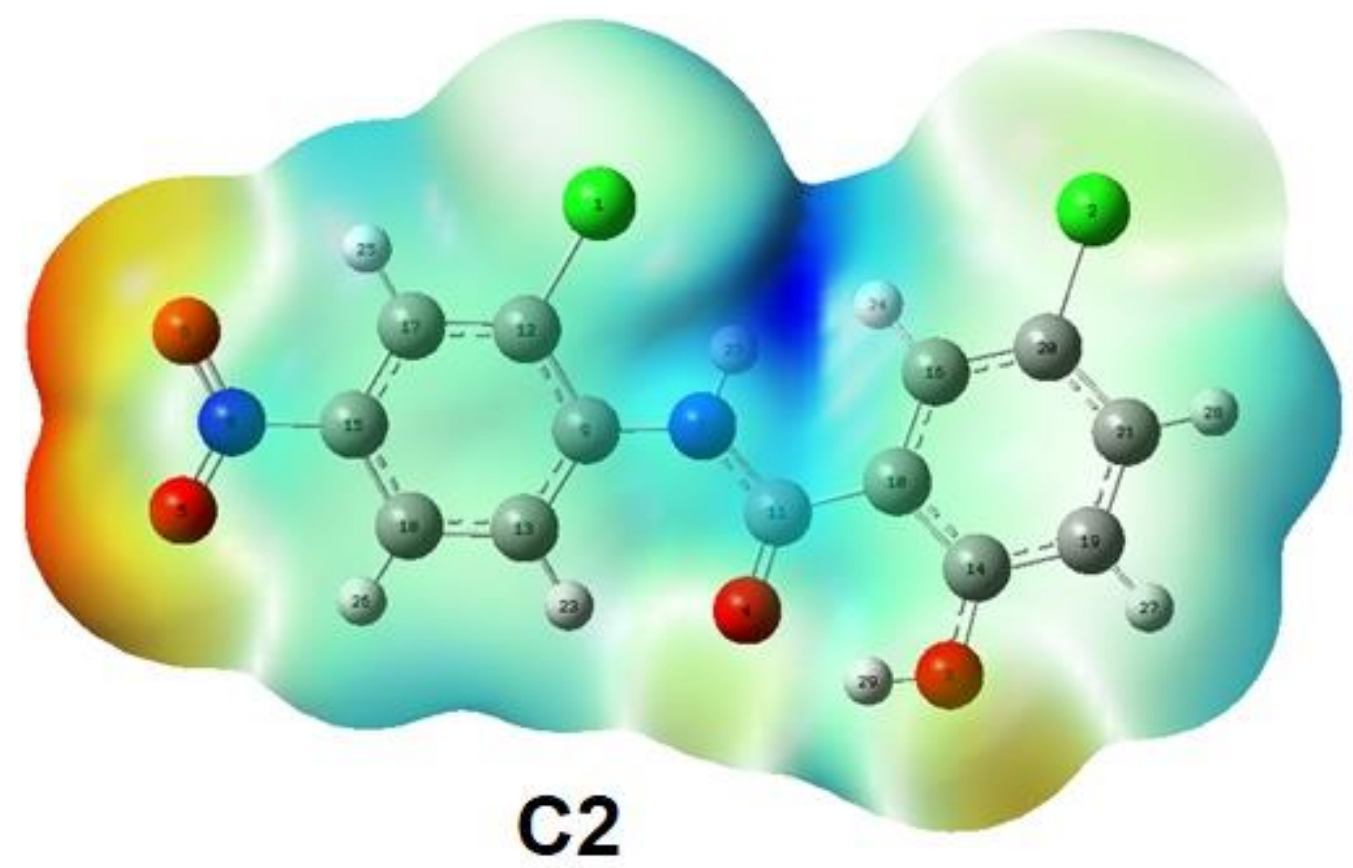

Figure S4. Calculated electrostatic potential surfaces on the molecular surfaces of $\mathrm{C} 1$ and $\mathrm{C} 2$ of niclosamide in gas phase. Color ranges \pm 0.0463 a.u. B3LYP functional and $6-31 G^{*}$ basis set. Isodensity value of 0.004 . 

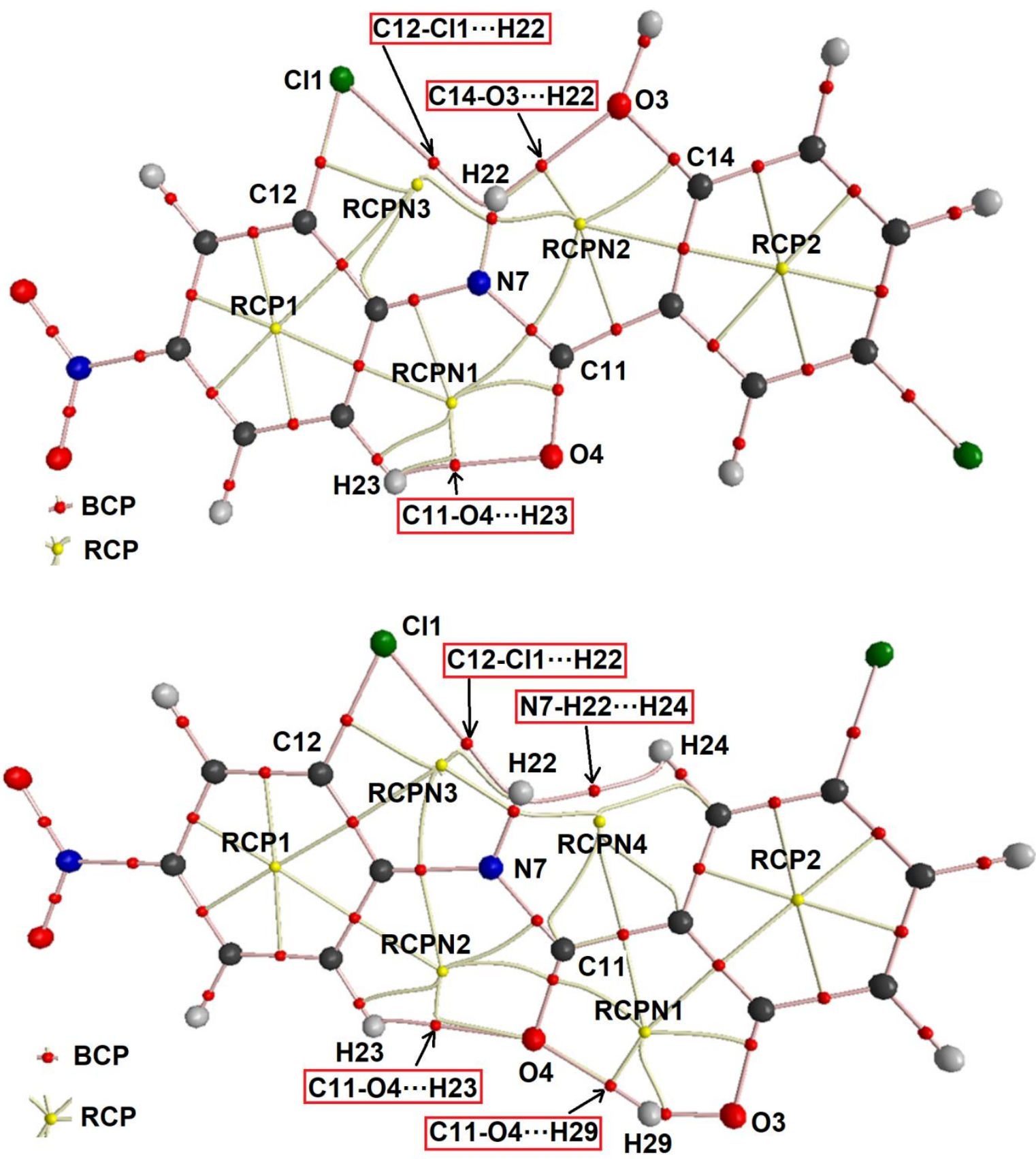

Figure S5. Molecular graphics of conformers C1 (upper) and C2 (bottom) of antiviral agent niclosamide in gas phase showing the geometry of all their bond critical points (BCPs) and ring critical points (RCPs) at the $\mathrm{B} 3 \mathrm{LYP} / 6-31 \mathrm{G}^{*}$ level of theory. 


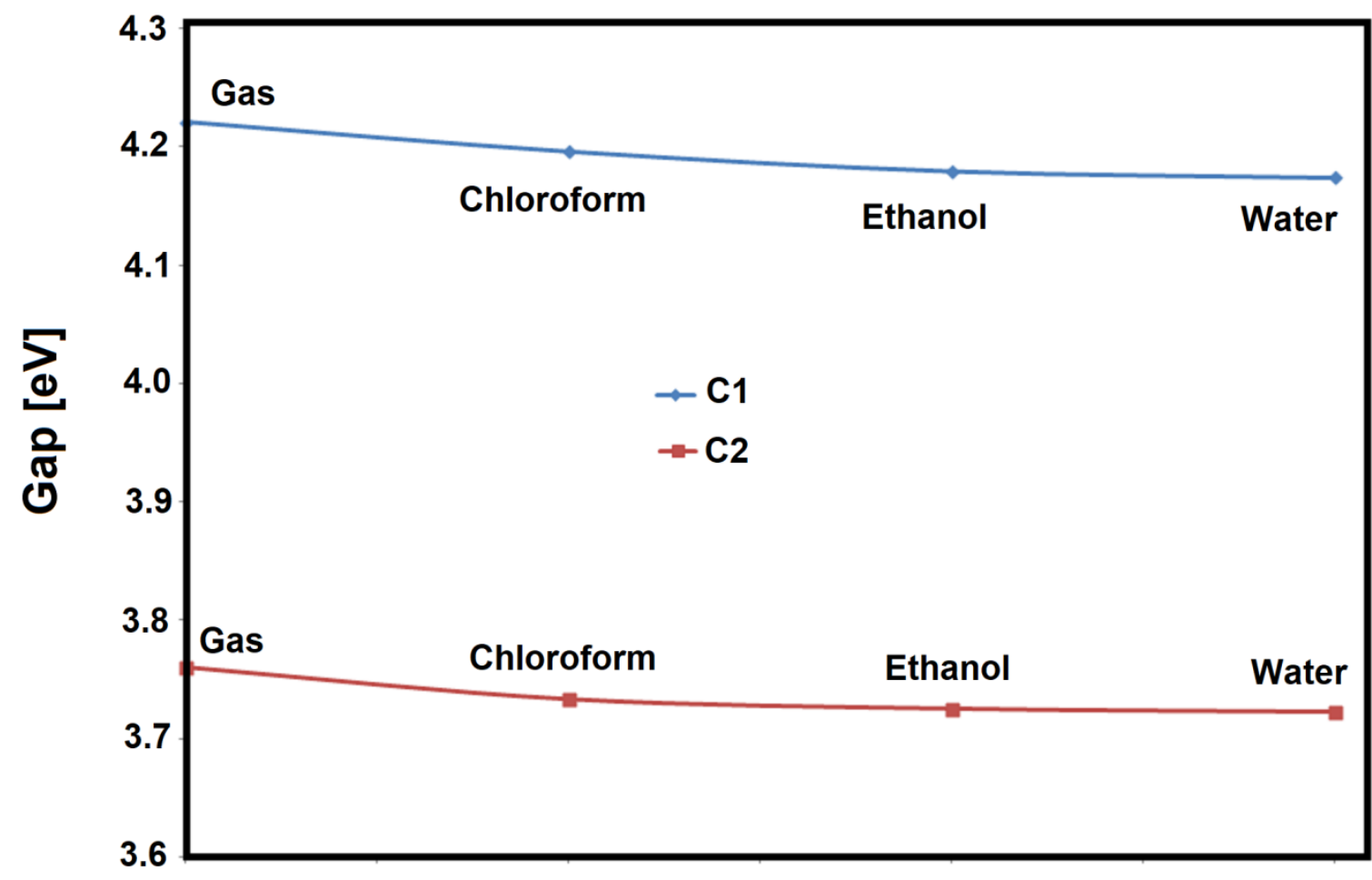

Figure S6. Calculated gap values for $\mathrm{C} 1$ and $\mathrm{C} 2$ of niclosamide in gas phase and in chloroform, ethanol and aqueous solutions by using the B3LYP/6-31G* method.
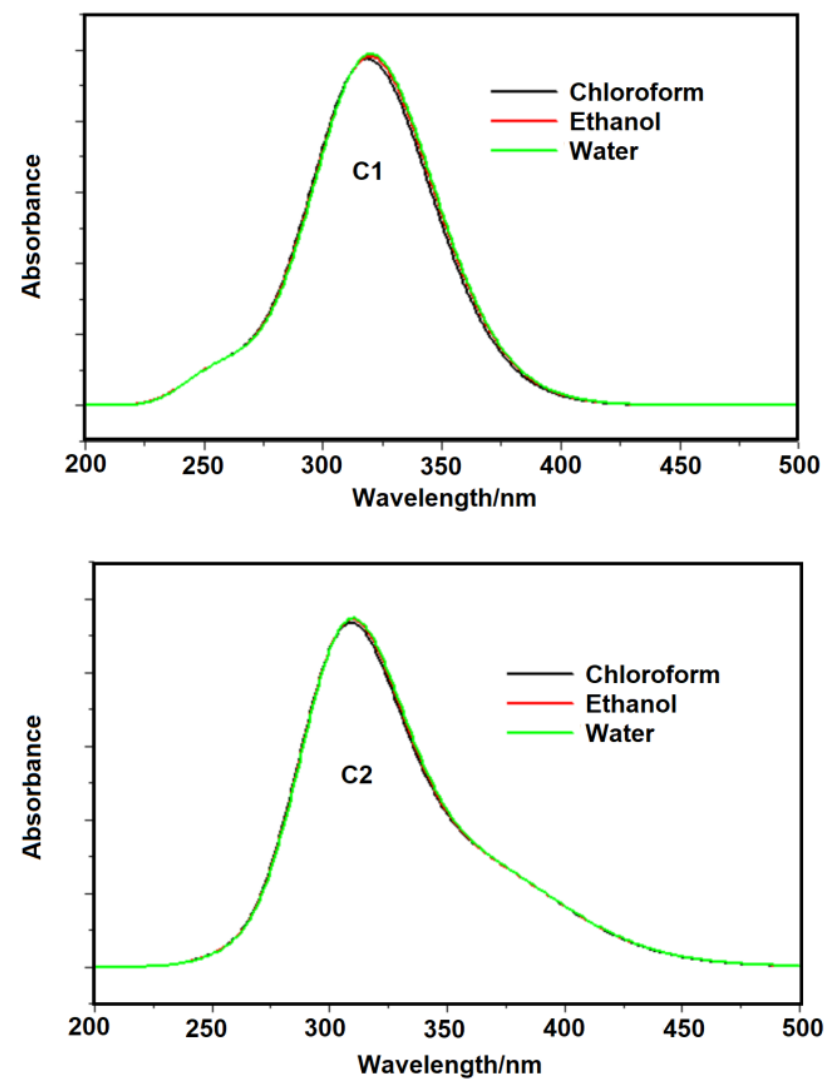

Figure S7. Predicted electronic spectra of $\mathrm{C} 1$ and $\mathrm{C} 2$ of niclosamide in chloroform, ethanol and aqueous solutions by using the B3LYP/6-31G* method. 